\title{
Cloud detection and classification based on MAX-DOAS observations
}

\author{
T. Wagner ${ }^{1}$, A. Apituley ${ }^{2}$, S. Beirle ${ }^{1}$, S. Dörner ${ }^{1}$, U. Friess ${ }^{3}$, J. Remmers ${ }^{1}$, and R. Shaiganfar ${ }^{1}$ \\ ${ }^{1}$ Max Planck Institute for Chemistry, Mainz, Germany \\ ${ }^{2}$ Royal Netherlands Meteorological Institute (KNMI), De Bilt, the Netherlands \\ ${ }^{3}$ Institute for Environmental Physics, University of Heidelberg, Heidelberg, Germany
}

Correspondence to: T. Wagner (thomas.wagner@mpic.de)

Received: 22 October 2013 - Published in Atmos. Meas. Tech. Discuss.: 3 December 2013

Revised: 2 April 2014 - Accepted: 3 April 2014 - Published: 19 May 2014

\begin{abstract}
Multi-axis differential optical absorption spectroscopy (MAX-DOAS) observations of aerosols and trace gases can be strongly influenced by clouds. Thus, it is important to identify clouds and characterise their properties. In this study we investigate the effects of clouds on several quantities which can be derived from MAX-DOAS observations, like radiance, the colour index (radiance ratio at two selected wavelengths), the absorption of the oxygen dimer $\mathrm{O}_{4}$ and the fraction of inelastically scattered light (Ring effect). To identify clouds, these quantities can be either compared to their corresponding clear-sky reference values, or their dependencies on time or viewing direction can be analysed. From the investigation of the temporal variability the influence of clouds can be identified even for individual measurements. Based on our investigations we developed a cloud classification scheme, which can be applied in a flexible way to MAX-DOAS or zenith DOAS observations: in its simplest version, zenith observations of the colour index are used to identify the presence of clouds (or high aerosol load). In more sophisticated versions, other quantities and viewing directions are also considered, which allows subclassifications like, e.g., thin or thick clouds, or fog. We applied our cloud classification scheme to MAX-DOAS observations during the Cabauw intercomparison campaign of Nitrogen Dioxide measuring instruments (CINDI) campaign in the Netherlands in summer 2009 and found very good agreement with sky images taken from the ground and backscatter profiles from a lidar.
\end{abstract}

\section{Introduction}

Clouds have a strong influence on the atmospheric radiative transfer and thus affect the interpretation and analysis of Multi-axis differential optical absorption spectroscopy (MAX-DOAS) observations (e.g. Erle et al., 1995; Wagner et al., 1998, 2004, 2011; Winterrath et al., 1999). In the forward model used for the inversion of aerosol and trace gas profiles (e.g. Wittrock et al., 2004; Heckel et al., 2005; Frieß et al., 2006; Irie et al., 2008; Clémer et al., 2010; Li et al., 2010; Wagner et al., 2011), a cloud-free atmosphere is usually assumed. Thus, if clouds are present during the measurements, this assumption in the forward model is not fulfilled, which can cause large errors of the retrieved profiles. For such measurements the cloud influence usually constitutes the largest error. Cloud effects are of particular importance if broken clouds are present. Then, measurements at some elevation angles might "see" clouds, while others do not. For these reasons it is of high importance to identify cloud-contaminated measurements. Such measurements could then, e.g., be skipped from further processing, or modified inversion approaches could be applied. At least cloud contaminated measurements could be assigned with a warning (cloud flag). Here it is interesting to note that, in principle, clouds could be included in the forward models, but there is usually not sufficient information on the cloud properties available to properly account for the cloud effects.

In this study we investigate how clouds affect several quantities which can be derived from MAX-DOAS observations, e.g. the measured radiance, a so-called colour index, the absorption of the oxygen dimer $\mathrm{O}_{4}$, and the Ring 
effect (the so-called "filling-in" of solar Fraunhofer lines; see Grainger and Ring, 1961). Based on these investigations we propose a cloud detection and classification algorithm, which allows automatic identification and classification of clouds. Cloud information derived from the MAX-DOAS observation (in contrast to the use of other sources like, e.g., visual inspection or camera images) is very important, because the cloud information can be directly assigned to individual MAX-DOAS observations without any spatio-temporal interpolation.

There are several ways to identify the presence of clouds: cloud effects can be identified by comparing the derived quantities for a given observation with their clear-sky reference values, which can be determined either from measurements in clear-sky conditions (for exactly the same viewing geometry) or from radiative transfer simulations (Sects. 3.13.4). The presence of clouds can also be deduced from the temporal variation of the derived quantities, because usually cloud properties and thus their effects on the MAXDOAS measurements change rapidly (on the order of minutes). From the observed dependence on the elevation angle the presence of clouds, in particular broken clouds, can also be identified.

Zenith observations (elevation angle of $90^{\circ}$ ) are especially useful for cloud detection: first, they only depend on the solar zenith angle (SZA), and not on the azimuth angle between the viewing direction and the sun. Thus, a direct comparison of zenith observations with the respective clear-sky reference values is simple and straightforward. Second, because the horizontal extension of clouds is usually much larger than their vertical extension, the temporal variability of the retrieved quantities caused by clouds is highest for zenith observations. For these reasons zenith observations constitute the most important part of our cloud classification scheme (see also Gielen et al., 2013).

In this study we investigate the influence of clouds on MAX-DOAS measurements based on radiative transfer simulations and real measurements. The MAX-DOAS measurements were performed during the Cabauw Intercomparison campaign of Nitrogen Dioxide measuring Instruments (CINDI) in summer 2009 (Piters et al., 2012). During CINDI AErosol RObotoc NETwork (AERONET) measurements of the aerosol optical depth (for a clear sky) were also available. Independent cloud information is derived from three main sources: (a) images taken from the moderate resolution imaging spectroradiometer (MODIS) satellite instrument, (b) images taken from a ground-based web camera in the direction of the MAX-DOAS observation (time resolution of about $10 \mathrm{~min}$ ), and (c) backscatter profiles from a zenith sky lidar.

The paper is organised as follows: in Sect. 2 the data sets (measurements during CINDI and atmospheric radiative transfer simulations) are introduced. In Sect. 3 the influence of clouds on the quantities derived from MAXDOAS observations is discussed in detail. Section 4 presents recommendations for an automatic cloud classification algorithm. The conclusions are given in Sect. 5 .

\section{Data sets and methods}

\subsection{MAX-DOAS observations during the Cabauw Intercomparison campaign of Nitrogen Dioxide measuring Instruments (CINDI), summer 2009}

We investigate the effect of clouds on MAX-DOAS measurements from measurements of a so-called Mini-MAX-DOAS instrument operated during CINDI (Piters et al., 2012; see also http://www.knmi.nl/samenw/cindi/); measurements are analysed for the period 12 June to 15 July 2009. The MiniMAX-DOAS instrument is described in detail in Hönninger et al. (2004) and Roscoe et al. (2011); the most important properties of our instrument are summarised below. The instrument covers a spectral range from 320 to $460 \mathrm{~nm}$ with a spectral resolution of $0.7 \mathrm{~nm}$. The instrument is temperature stabilised; the field of view is $\sim 1.2^{\circ}$.

During CINDI, the Mini-MAX-DOAS instrument was mounted at the Cabauw tower (http: //www.cesar-observatory.nl/) at an altitude of about $20 \mathrm{~m}$. It was directed in a west-north-westerly direction $\left(287^{\circ}\right.$ with respect to north). The instrument performed measurements at sequences of 12 elevation angles $\left(-20^{\circ},-5^{\circ},-0.5^{\circ}, 0^{\circ}\right.$, $2^{\circ}, 4^{\circ}, 6^{\circ}, 8^{\circ}, 10^{\circ}, 15^{\circ}, 30^{\circ}, 85^{\circ}$ ); a full elevation sequence usually took about $12 \mathrm{~min}$. The zero and negative elevation angles were chosen to analyse light reflected at the surface; they are not used in this study. Since our instrument was mounted directly at the tower, we used slightly off-zenith observations (elevation angle of $85^{\circ}$ ) instead of exactly $90^{\circ}$ to avoid shielding and reflections from the tower. In spite of the rather small deviation from the exact zenith direction, especially the measured radiance, a so-called colour index (CI) and the Ring effect are significantly different from those obtained for exactly zenith direction (see Sect. 3). In addition, it should be noted that before 22 June 2009 our instrument was slightly misaligned (the elevation angles were about one degree too low). After 22 June 2009 this misalignment was corrected. Fortunately, this "jump" of the elevation adjustment can be neglected in this study for two reasons: (a) absolute comparisons are only made for measurements at (near-) zenith view, for which a deviation of $1^{\circ}$ causes only a negligible relative change $(<1 \%)$ of the derived quantities. (b) measurements at off-zenith viewing directions are only analysed in a semiquantitative way (for details see below), for which a deviation of $1^{\circ}$ can also be neglected. Measurements were performed for $\mathrm{SZA}<95^{\circ}$, but in this study only measurements for $\mathrm{SZA}<75^{\circ}$ are considered in our cloud classification scheme (see below).

The following quantities are investigated in this study:

- the measured radiance at $360 \mathrm{~nm}$ in units of counts $\mathrm{s}^{-1}$ (Sect. 3.1); 
- the colour index (ratio of intensities at $320 \mathrm{~nm}$ and $440 \mathrm{~nm}$, Sect. 3.2);

- the absorption of the oxygen dimer $\mathrm{O}_{4}$ at $360 \mathrm{~nm}$ (Sect. 3.3);

- the strength of the Ring effect (Sect. 3.4).

The $\mathrm{O}_{4}$ absorption and the Ring effect are analysed in the wavelength range 353 to $390 \mathrm{~nm}$. Besides the Ring spectrum (Wagner et al., 2009) and the $\mathrm{O}_{4}$ cross section (Greenblatt et al., 1990), cross sections of $\mathrm{NO}_{2}$ at $298 \mathrm{~K}$ (Vandaele et al., 1996) and $\mathrm{O}_{3}$ at $223 \mathrm{~K}$ (Bogumil et al., 2003) as well as a polynomial of degree 5 and a constant intensity offset are included in the spectral analysis (Platt and Stutz, 2008). A fixed Fraunhofer reference spectrum (from 24 June 2009, 11:36 UTC) measured in zenith direction is used for the analysis of all measurements.

\subsection{Radiative transfer simulations}

The fully spherical Monte Carlo radiative transfer model McARTIM (Monte Carlo atmospheric radiative transfer inversion model) (Deutschmann et al., 2011) was used to simulate the effects of clouds and aerosols on the quantities retrieved from the MAX-DOAS observations. For these simulations a surface albedo of $5 \%$ was assumed. The scattering on aerosol and cloud particles was approximated by a Henyey-Greenstein phase function with asymmetry parameters of 0.68 and 0.85 , respectively. These are typical values for clouds and pollution aerosols (see, e.g., Nakajima and King, 1990, and Dubovik et al., 2002); the actual choice is not critical for our study. Besides the simulated (normalised) radiances we also calculated the color index (CI) (ratio of intensities at 320 and $440 \mathrm{~nm}$ ) and the air mass factor for the oxygen dimer $\mathrm{O}_{4}$. The strength of the Ring effect can be described by the so-called Raman scattering probability (RSP; see Wagner et al., 2009), which is directly derived from the McARTIM simulations. Note that for simplicity radiance, $\mathrm{O}_{4}$ air mass factor (AMF) and Ring effect were all simulated for the same wavelength $(360 \mathrm{~nm})$. Since the Ring effect and the $\mathrm{O}_{4}$ absorption are analysed over a larger wavelength range (353-390 nm), this might lead to small differences between the measured and modelled values. But these differences are not of importance here.

\subsection{Satellite images and camera images}

We used visual images from satellite and a groundbased camera to characterise the regional cloud properties during CINDI. RGB (red green blue) satellite images from the Moderate Resolution Imaging Spectroradiometer (MODIS) on the TERRA satellite, taken shortly before local noon, are obtained from NASA's Goddard Space Flight Center (NASA/GSFC), MODIS Rapid Response, http:// aeronet.gsfc.nasa.gov/cgi-bin/bamgomas_interactive. From these images an overview of the general cloud coverage and structure over the measurement site is obtained.

In addition, continuous ( $10 \mathrm{~min}$ intervals) images of a ground-based digital camera operated by the Institute for Environmental Physics at the University of Heidelberg were used. These images were taken in the same direction of the MAX-DOAS instrument, but covered only a fraction of the sky: from the horizon to an elevation angle of about $37^{\circ}$ and over an azimuth angle range between about $262^{\circ}$ and $312^{\circ}$ with respect to north.

\subsection{Aerosol optical depth from the AERONET instrument}

A sun photometer from the Aerosol Robotic Network (AERONET, http://aeronet.gsfc.nasa.gov/) is operated at Cabauw (http://aeronet.gsfc.nasa.gov/new_web/photo_db/ Cabauw.html), operated by J. S. Henzing. Information on the AERONET observational network can be found in Holben et al. (2001). In this study we use Level 2.0 data of the aerosol optical depth at $360 \mathrm{~nm}$. Typical integration times are 2 to $15 \mathrm{~min}$. Note that aerosol retrievals are possible for clear, but also partly cloudy situations as long as direct sunlight can be observed. Note that the viewing geometry of the AERONET instrument is different from that of MAX-DOAS instrument.

\subsection{Lidar backscatter profiles}

Deployed at the Cabauw Experimental Site for Atmospheric Research (CESAR; see http://www.cesar-observatory.nl/) in May 2000, a backscatter lidar measures aerosol and cloud profiles from which the planetary boundary layer heights (PBL) and cloud cover can be estimated (Apituley, 2000; Schaap, 2009). The lidar is placed at a distance of about $350 \mathrm{~m}$ away from the meteorological tower. The pointing direction is nominally to zenith.

The backscatter lidar is based on a $10 \mathrm{~Hz} \mathrm{Nd:YAG} \mathrm{laser,}$ emitting at $1064 \mathrm{~nm}$. The backscattered light is collected by a $30 \mathrm{~cm}$ diameter telescope based on a Fresnel lens and detected by an avalanche photo diode. The lidar geometry provides full overlap between the laser beam and the receiver field of view upwards of an altitude of about $150 \mathrm{~m}$.

The data collection scheme was designed for following PBL developments and samples the atmosphere for $25 \mathrm{~s} \mathrm{ev-}$ ery $5 \mathrm{~min}$. Note that this scheme has a duty cycle of about $8 \%$. For cloud detection, the $25 \mathrm{~s}$ average profile is used. Well-developed cirrus clouds can be detected up to a height of $15 \mathrm{~km}$ - contrails and very thin cirrus will be lost in noise. All low- and mid-level clouds are always detected.

It should be noted that partial overlap exists at altitudes below $150 \mathrm{~m}$. In the case of very strong scattering close to the ground, e.g. in the case of fog or heavy precipitation, strong signals can be received, even in the region of partial overlap. In particular in the case of fog, these strong signals will overload the detector, which results in nonphysical 
a) MODIS RGB image

$11: 30$

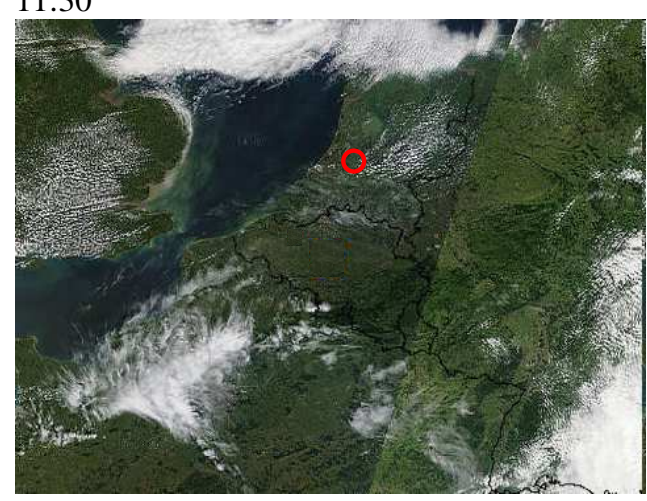

c) Radiance and aerosol optical depth

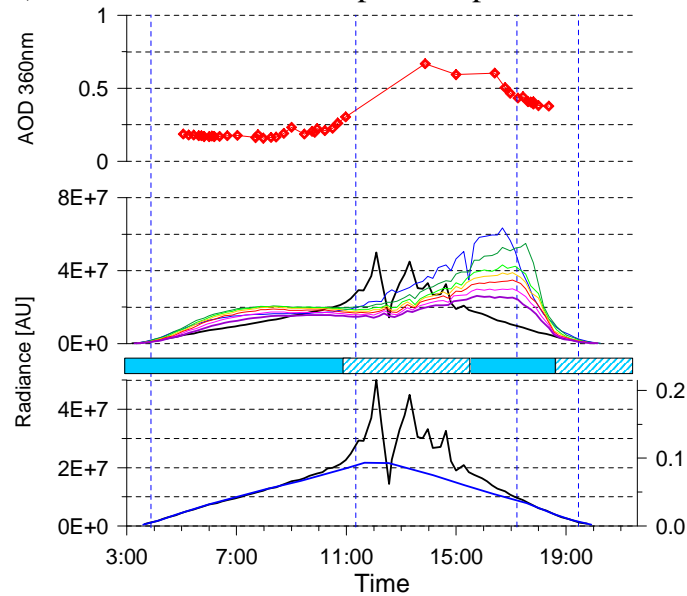

e) $\mathrm{O}_{4}$ absorption

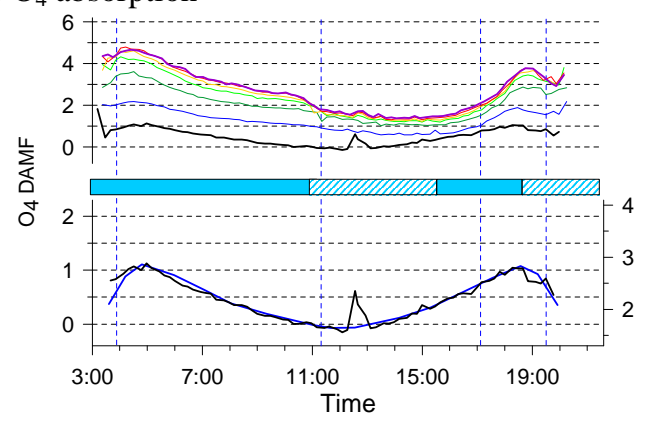

b) Ground-based camera

$3: 51$

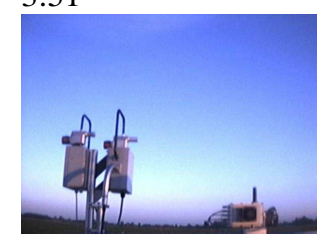

$17: 11$

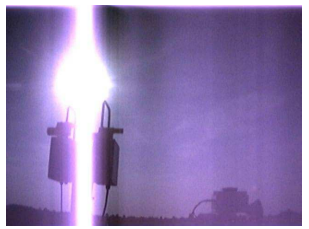

d) Colour Index
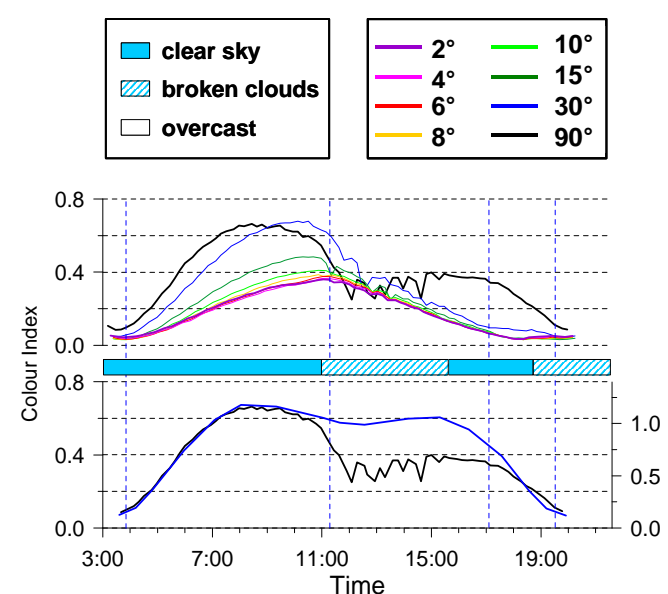

f) Ring effect

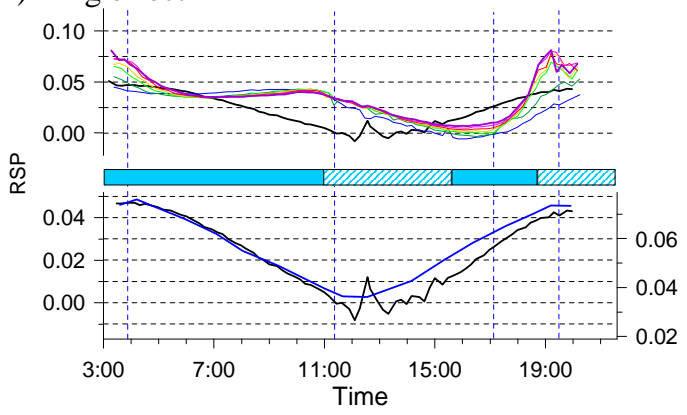

Fig. 1. Cloud images (a: from satellite, b: from the ground) and diurnal variations of several retrieved quantities from MAX-DOAS observations for a mostly clear day (24 June 2009): (c) measured radiance and aerosol optical depth at $360 \mathrm{~nm}$; (d) colour index; (e) $\mathrm{O}_{4}$ absorption; (f) Ring effect. In the upper parts of (c)-(f), the results for all elevation angles are shown (for elevation angles, see legend in d). In the bottom parts the results for zenith view together with the clear-sky reference values (blue lines) are shown. The horizontal bars in blue colours indicate the cloud properties derived from the images of the ground-based camera (time is given as UTC). DAMF: differential air mass factor; AOD: aerosol optical depth; AU: arbitrary units.

responses for atmospheric returns at higher altitudes. Some additional artifacts can be observed in the lidar signals (see Fig. 18) at around $2 \mathrm{~km}$ of altitude that are mainly due to the old age of the equipment. These artifacts, however, do not impede in any way the ability of the lidar to detect clouds, which is the main application of the data in this paper. The diurnal variation of the lidar backscatter profiles is used for comparison with the results of the MAX-DOAS cloud classification scheme. Note that during CINDI, a highperformance Raman lidar was operated at CESAR (Apituley, 2009). However, this system could not provide data continuously. 
Table 1. Overview on selected days during CINDI.

\begin{tabular}{ll}
\hline Day & Specific conditions \\
\hline 24 June 2009 (Fig. 1) & In the morning almost clear sky and low AOD \\
15 June 2009 (Fig. 2) & Completely overcast, optically thick clouds around noon \\
2 July 2009 (Fig. 3) & Mostly clear sky, but high AOD \\
28 June 2009 (Fig. 4) & Mainly overcast day, fog in the morning \\
18 June 2009 (Fig. 5) & Broken clouds in the morning \\
\hline
\end{tabular}

AOD: aerosol optical depth.

a) MODIS RGB image

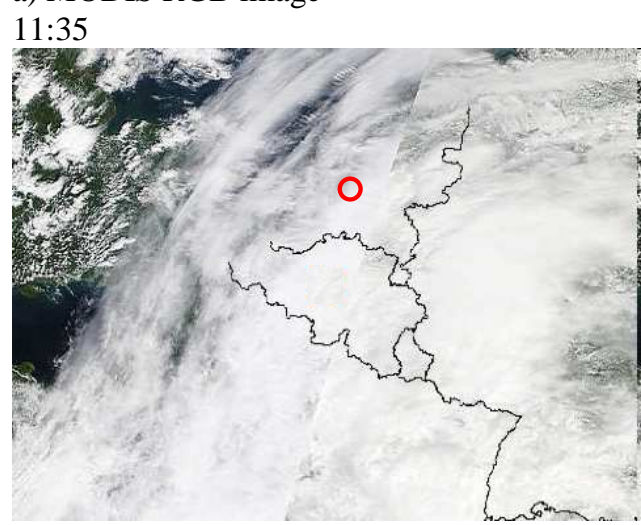

c) Radiance and aerosol optical depth

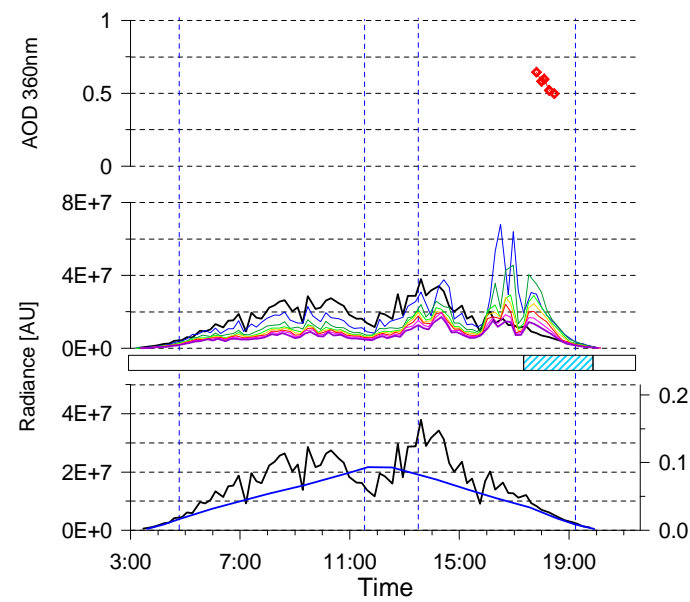

e) $\mathrm{O}_{4}$ absorption

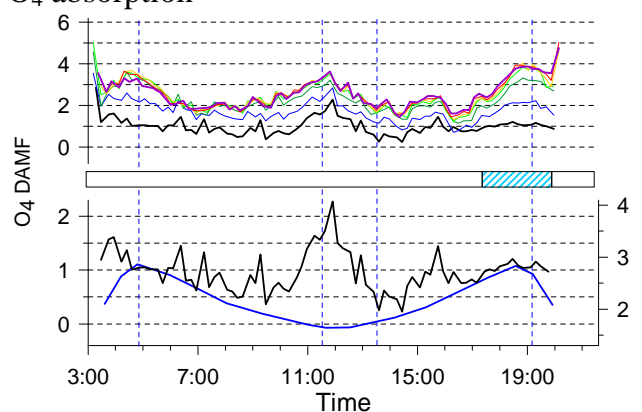

b) Ground-based camera
4:54

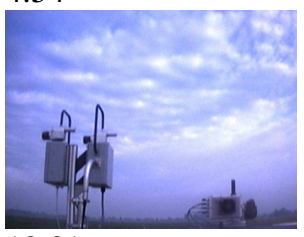

$13: 31$

d) Colour Index

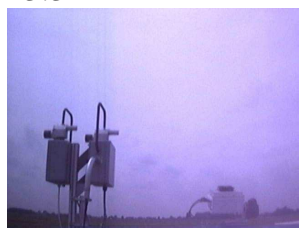

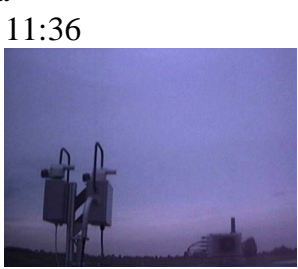

19:11

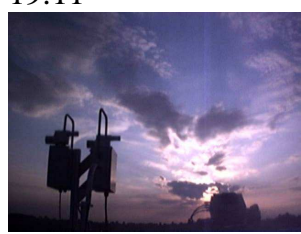

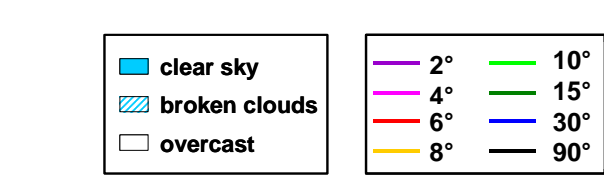

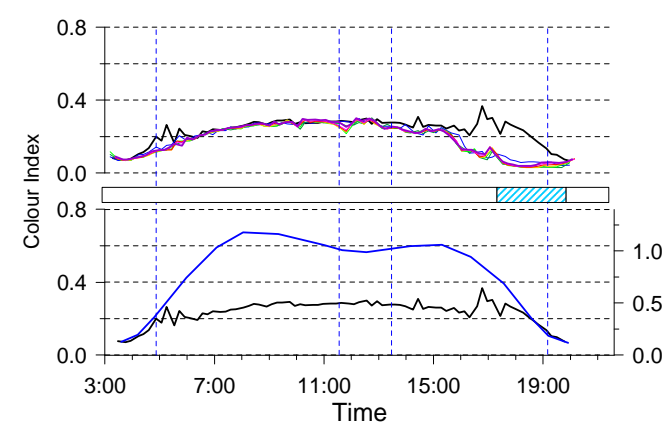

f) Ring effect

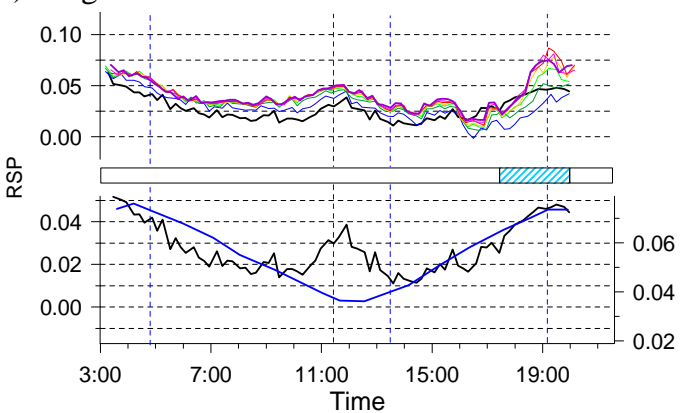

Fig. 2. Same as Fig. 1 but for an overcast day (15 June 2009). (Time is given as UTC.) 
a) MODIS RGB image

$10: 45$

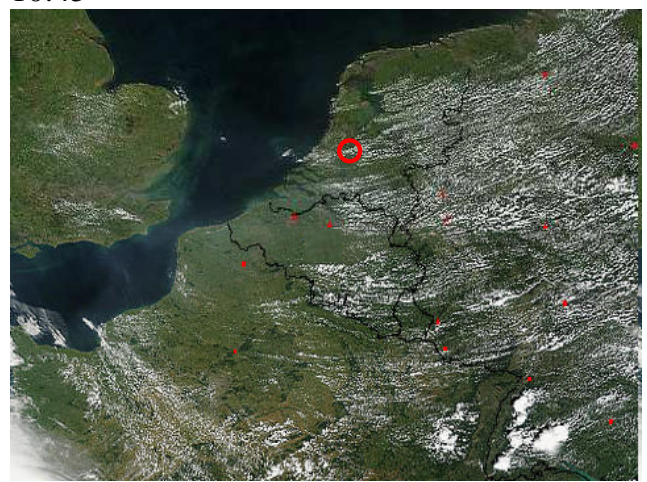

c) Radiance and aerosol optical depth

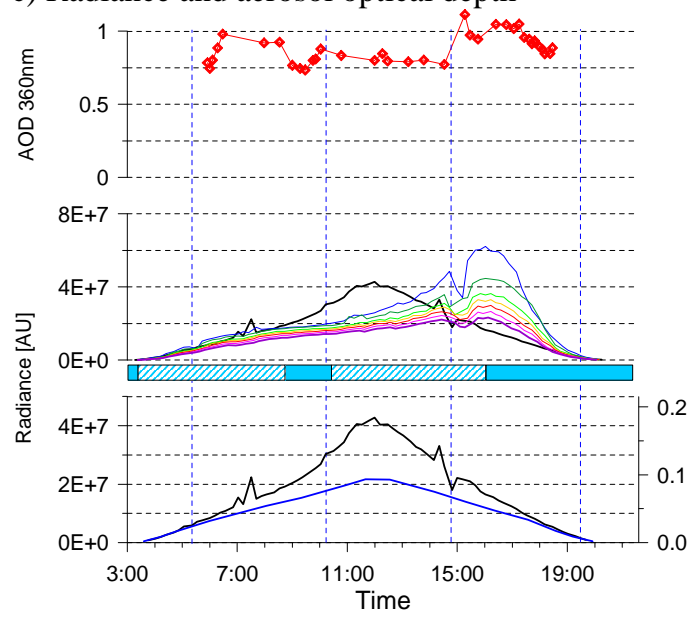

e) $\mathrm{O}_{4}$ absorption

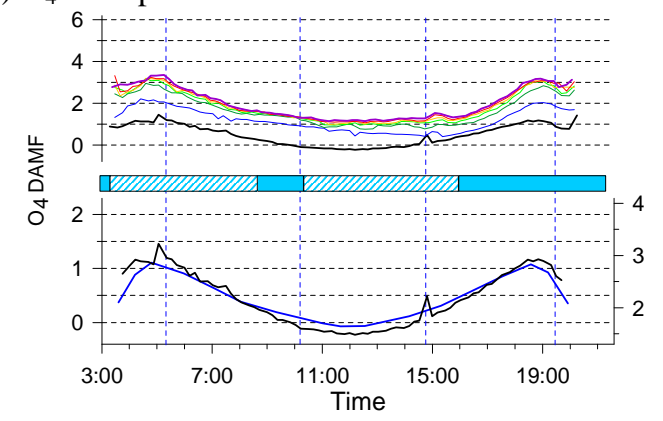

b) Ground-based camera

$5: 17$

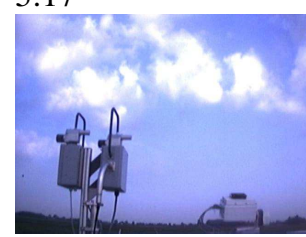

$14: 45$

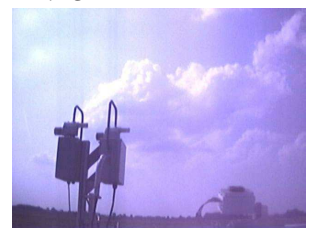

d) Colour Index
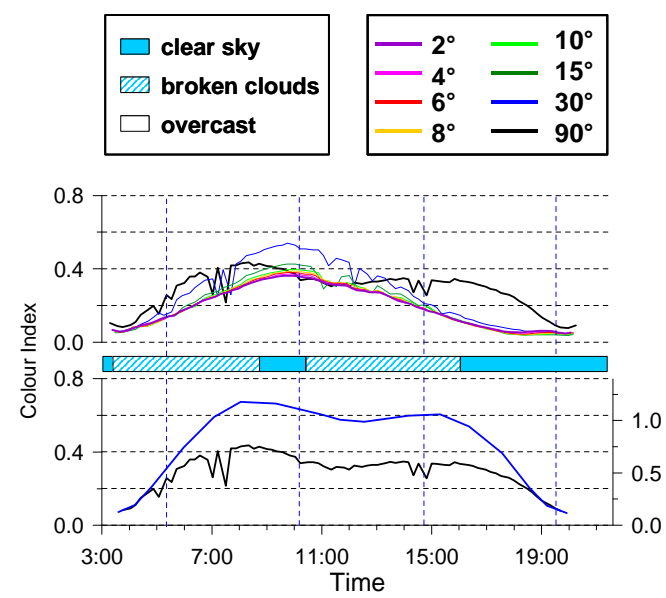

f) Ring effect

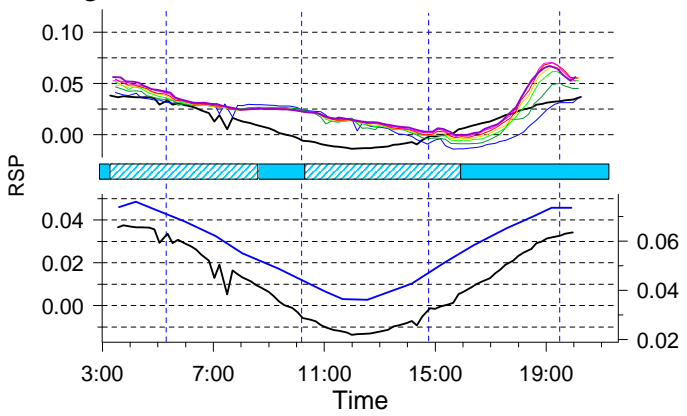

Fig. 3. Same as Fig. 1 but for a mainly clear day with high aerosol optical depth (2 July 2009). (Time is given as UTC.)

\section{Dependence of selected quantities derived from MAX-DOAS on cloud properties}

In this section the cloud influence on the measured radiance, the colour index, the $\mathrm{O}_{4}$ absorption and the Ring effect is investigated in detail. The cloud effects are illustrated by measurements made on five days representing different sky conditions (Figs. 1-5). The first two days represent rather simple cases with either mainly clear or cloudy skies; the later days represent more complex situations with, e.g., fog or broken clouds. An overview of the specific sky conditions during these days is given in Table 1 . The results of the four investigated quantities for these days are discussed in detail together with results from radiative transfer simulations in the following sections.

\subsection{Radiance}

For observations at high elevation angles, especially for zenith viewing direction, the optical depth in the UV and visible spectral range with respect to atmospheric Rayleigh 
a) MODIS RGB image
11:05

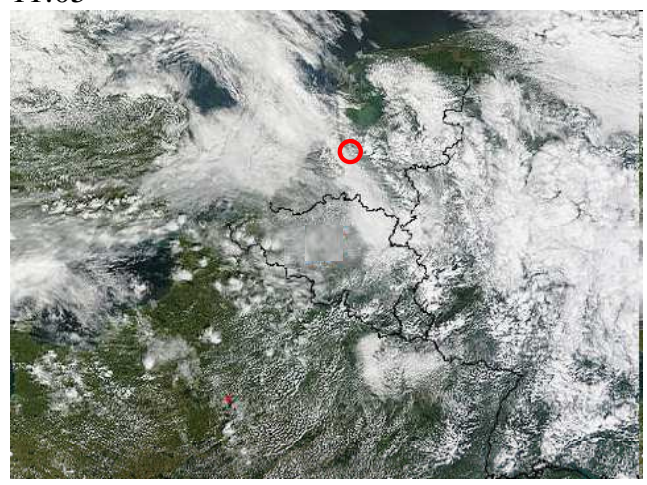

c) Radiance and aerosol optical depth

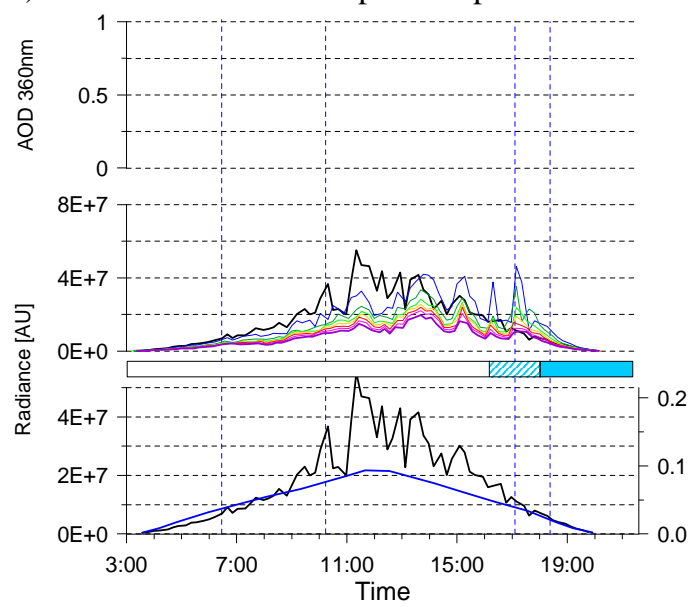

e) $\mathrm{O}_{4}$ absorption

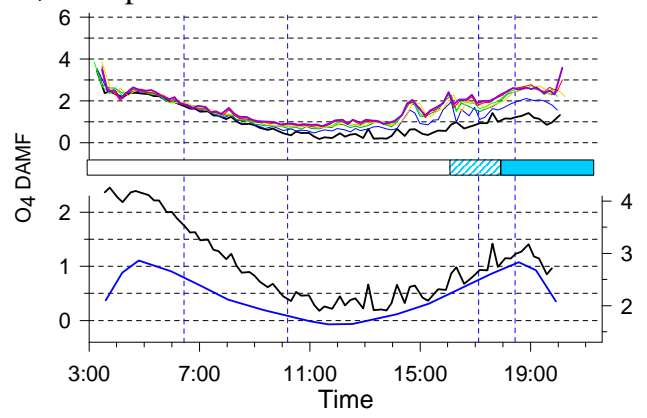

b) Ground-based camera

6:26

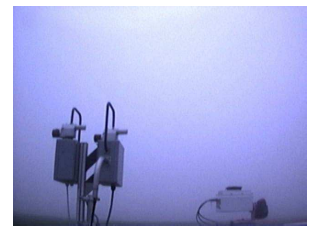

$17: 04$

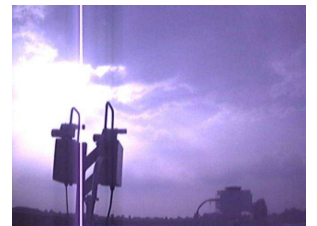

d) Colour Index
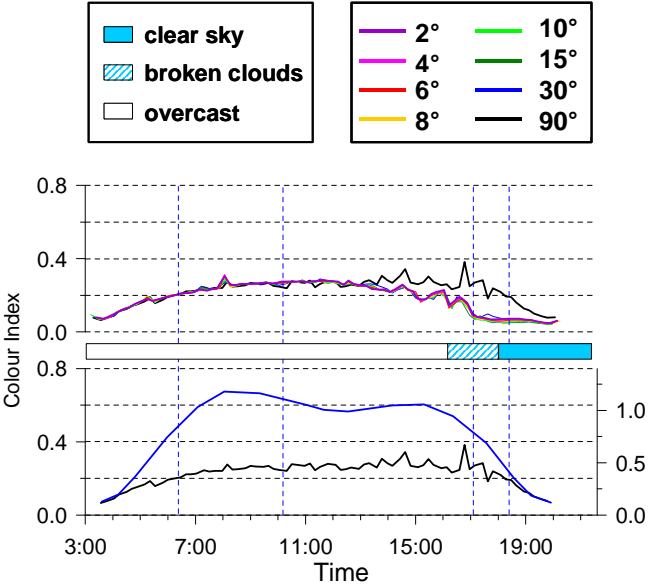

f) Ring effect

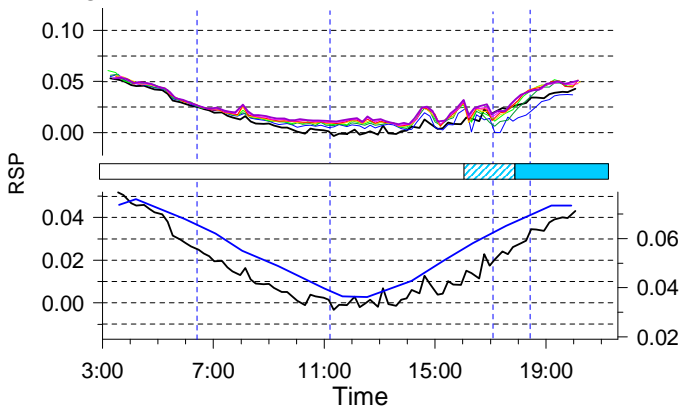

Fig. 4. Same as Fig. 1 but for a mainly overcast day with fog in the morning (28 June 2009). Due to the cloud cover, no AERONET AOD values are available for this day (Time is given as UTC.)

scattering is rather small. Thus, additional scattering on cloud (or aerosol) particles usually increases the observed radiance (exceptions can occur for thick clouds; see below). In contrast, for low elevation angles, especially at short wavelengths, the Rayleigh scattering optical depth is larger and thus clouds can either increase or decrease the observed radiance. The details of these dependencies vary with elevation angle, relative azimuth angle between the viewing direction and the sun (RAA) and the SZA. In Fig. 6 radiative transfer simulation results of the (normalised) radiance for an SZA of $30^{\circ}$ and $60^{\circ}$ and an RAA of $90^{\circ}$ are shown (similar dependencies are found for other viewing geometries). The output of McARTIM is given as normalised radiance $R_{\text {norm }}$, which is defined here as

$R_{\text {norm }}(\lambda)=\frac{R(\lambda)}{I(\lambda)}$,

with $R(\lambda)$ being the measured radiance and $I(\lambda)$ the solar irradiance. 
a) MODIS RGB image

12:10

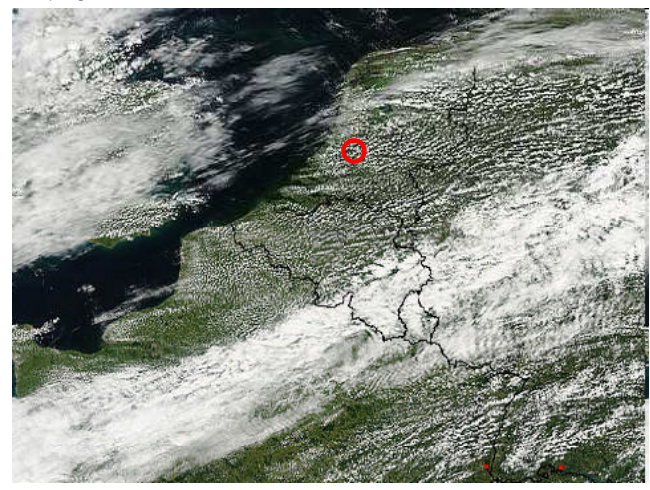

c) Radiance and aerosol optical depth

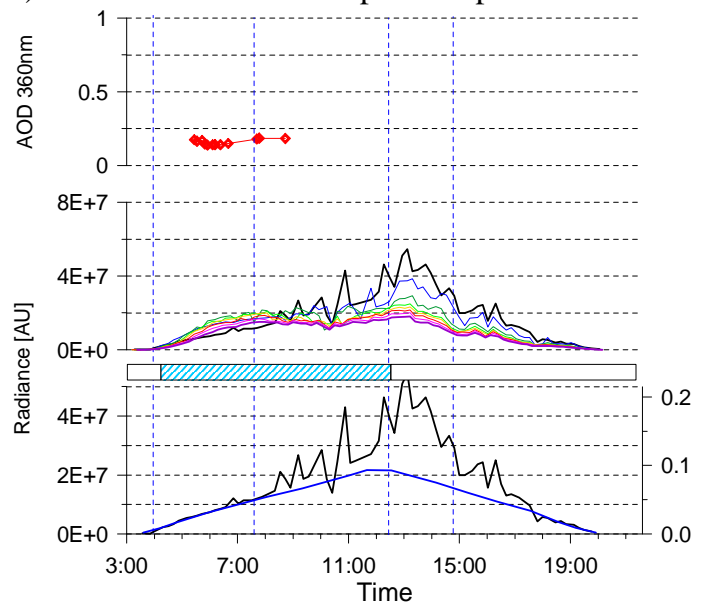

e) $\mathrm{O}_{4}$ absorption

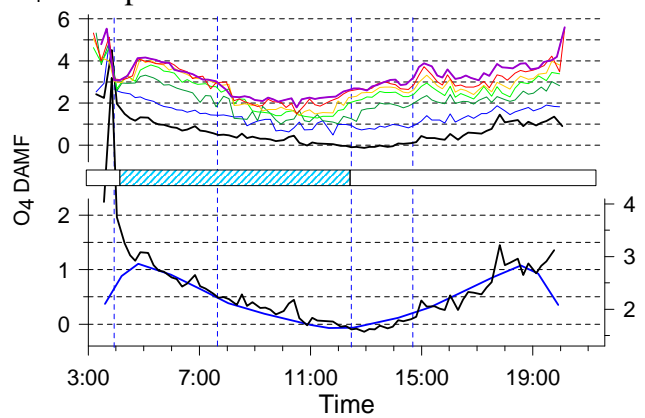

b) Ground-based camera

3:57

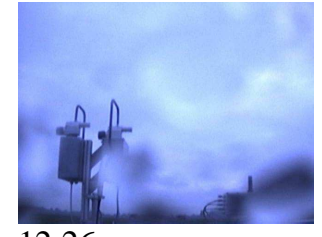

$12: 26$

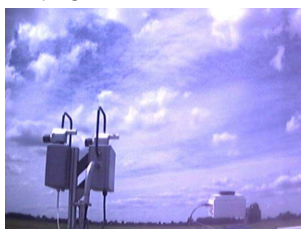

d) Colour Index
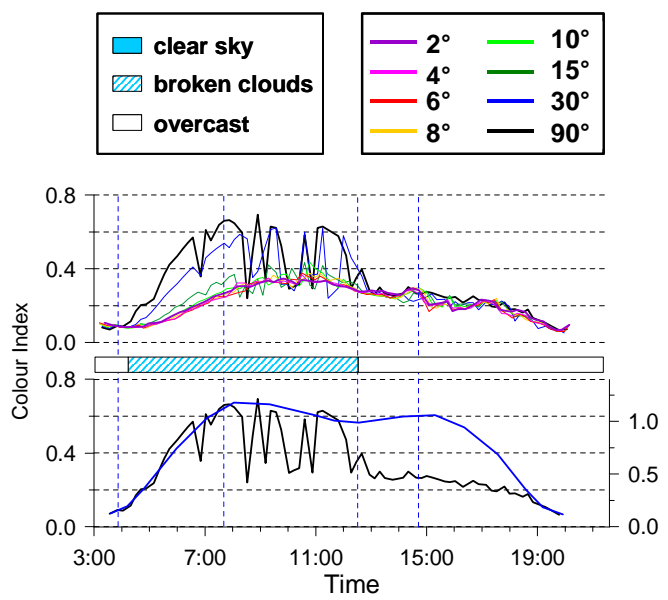

f) Ring effect

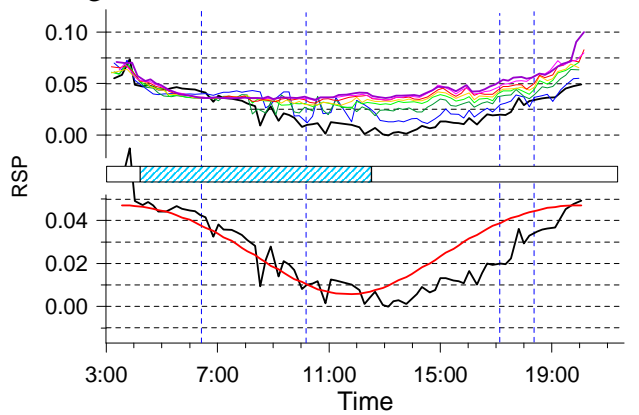

Fig. 5. Same as Fig. 1 but for a day with broken clouds during the morning (18 June 2009). (Time is given as UTC.)

One interesting finding from the radiative transfer simulations (Fig. 6) is that although zenith observations are especially well suited to detect the presence of clouds, cloud detection from zenith observations is still not unambiguous: in the case of optically thick clouds (OD > about 50), the observed radiance decreases and can even reach values smaller than for a clear sky.

The results from the radiative transfer simulations are confirmed by the MAX-DOAS measurements during CINDI (Figs. 1-5); some examples are discussed in detail in the following. In Fig. 1c the measured radiance at $360 \mathrm{~nm}$ for 24 June 2009 is shown. This day was mostly clear as indicated by the visible images from satellite and from the ground (Fig. 1a and b). During the completely cloud-free parts of that day (morning and part of the afternoon), the measured radiance shows a smooth temporal variation. The radiance for the high elevation angles are smaller than those measured at low elevation angles, because of the smaller atmospheric optical depth along the line of sight for high elevation angles (except when clouds are present). In the upper 

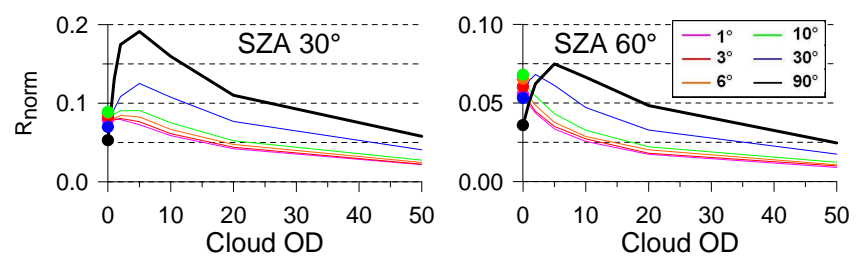

Fig. 6. Normalised radiance at $360 \mathrm{~nm}$ as function of the cloud optical depth for various elevation angles (see legend) derived from radiative transfer simulations. The filled circles show values for a clear sky. The cloud optical properties are described by the HenyeyGreenstein approximation with an asymmetry parameter of 0.85 and a single scattering albedo of 1 . The cloud layers range from 1 to $2 \mathrm{~km}$ for cloud OD of 1 to 20 , from 1 to $3 \mathrm{~km}$ for cloud OD of 20 and from 1 to $6 \mathrm{~km}$ for cloud OD of 50. The relative azimuth angle is $90^{\circ}$.

part of Fig. 1c the aerosol optical depth (AOD) at $360 \mathrm{~nm}$ measured by the AERONET sun photometer is shown. During the first (clear) half of the day the AOD is rather small (about 0.2 ), but it strongly increases in the afternoon. During noon, no AOD values are measured because of the presence of clouds. In the lower part of Fig. 1c the radiance for zenith view with the respective clear-sky reference values (see below) is shown.

In Fig. 7a the measured radiance for the same day, but only in (near-) zenith direction is shown. In addition to the measured values (black line), different clear-sky reference values are shown: the red line is a polynomial fit (as function of the SZA) to the measured clear-sky radiance during the (clear) morning (before 10:30 UTC). The blue and magenta lines are results from radiative transfer simulations for either exactly zenith (elevation angle of $90^{\circ}$ ) or the near-zenith view of our instrument (elevation angle of $85^{\circ}$ ), respectively. Both curves are slightly different: the afternoon values for $85^{\circ}$ are systematically higher than those for $90^{\circ}$, and vice versa in the morning. The higher (smaller) values in the afternoon (morning) are caused by the fact that during that part of the day the instrument (at an elevation angle of $85^{\circ}$ ) is directed slightly towards (away from) the sun.

Note that the radiative transfer simulations were performed assuming an aerosol layer from the surface to $1 \mathrm{~km}$ with an AOD of 0.3. This AOD value is slightly larger than that measured by the AERONET instrument (about 0.2). The most probable reason for this discrepancy is the neglect of polarisation in our radiative transfer model (see, e.g., Mishchenko et al., 1994). But deviations of the used asymmetry parameter (0.68), single scattering albedo (0.95) and vertical profile from the true aerosol properties might also play a role. In spite of this slight inconsistency, the comparison shown in Fig. 7 basically indicates that radiative transfer simulations are in principle well suited to serve as clear-sky reference values. In the following we use the results of the radiative transfer simulations as clear-sky reference values because they correctly describe the slight a.m./p.m. asymmetry of our (near-) zenith observations. Here it should be noted that the exact choice of the reference values shown in Fig. 7 is not critical.

Like typical DOAS instruments, our MAX-DOAS instrument is not radiometrically calibrated (note the different scales in Fig. 7). However, from the comparison of the measured and simulated radiance values during the (clear) morning, a proportionality constant can be derived which can be used for a rough conversion of the measurements (digital counts per second) into the normalised radiance (Eq. 1). For our measurements we derive a proportionality constant of $4.3 \times 10^{-9}$ with an estimated uncertainty of about $\pm 15 \%$.

Around noon on 24 June 2009, when clouds were present, the observed radiance is typically enhanced compared to the clear-sky values. For one observation, however, the radiance is even smaller than the clear-sky reference value indicating the presence of an optically thick cloud. In the late afternoon, when the sky was clear again, the radiance is systematically higher than the clear-sky reference values. This enhancement is mainly caused by the increase of the aerosol optical depth during the second half of the day.

In Fig. 2 results for an almost overcast day (15 June 2009) are shown; only in the late afternoon were there some holes in the cloud cover. For zenith direction (Fig. 2c), the radiance is mostly increased compared to the clear-sky reference values. But again, around noon the measured radiance becomes smaller than for clear-sky conditions indicating optically thick clouds. Similar cloud effects on the measured radiance are also found for the other selected days (Figs. 3$5)$.

\subsection{Colour index (CI)}

A colour index (or colour ratio) is usually defined as the ratio of two radiance values at different wavelengths (e.g. Sarkissian et al., 1991, 1994; Enell et al., 1999). In this study we calculate CI from measured detector signals at $320 \mathrm{~nm}$ and $440 \mathrm{~nm}$ :

$\mathrm{CI}_{\text {meas }}=\frac{S(320 \mathrm{~nm})}{S(440 \mathrm{~nm})}$.

Here, $S(\lambda)$ indicates the measured detector signal at wavelength $\lambda$. Since the efficiencies of the grating and the detector usually depend on wavelength, $\mathrm{CI}_{\text {meas }}$ derived from the measurements do not equal the $\mathrm{CI}$ calculated from calibrated atmospheric radiance measurements or from radiative transfer simulations:

$\mathrm{CI}=\frac{R(320 \mathrm{~nm})}{R(440 \mathrm{~nm})}$.

Thus, no direct comparison of measured $\mathrm{CI}_{\text {meas }}$ and the $\mathrm{CI}$ derived from radiative transport simulations is possible, but both CIs are proportional:

$\mathrm{CI}=\mathrm{CI}_{\text {meas }} \cdot \beta$, 

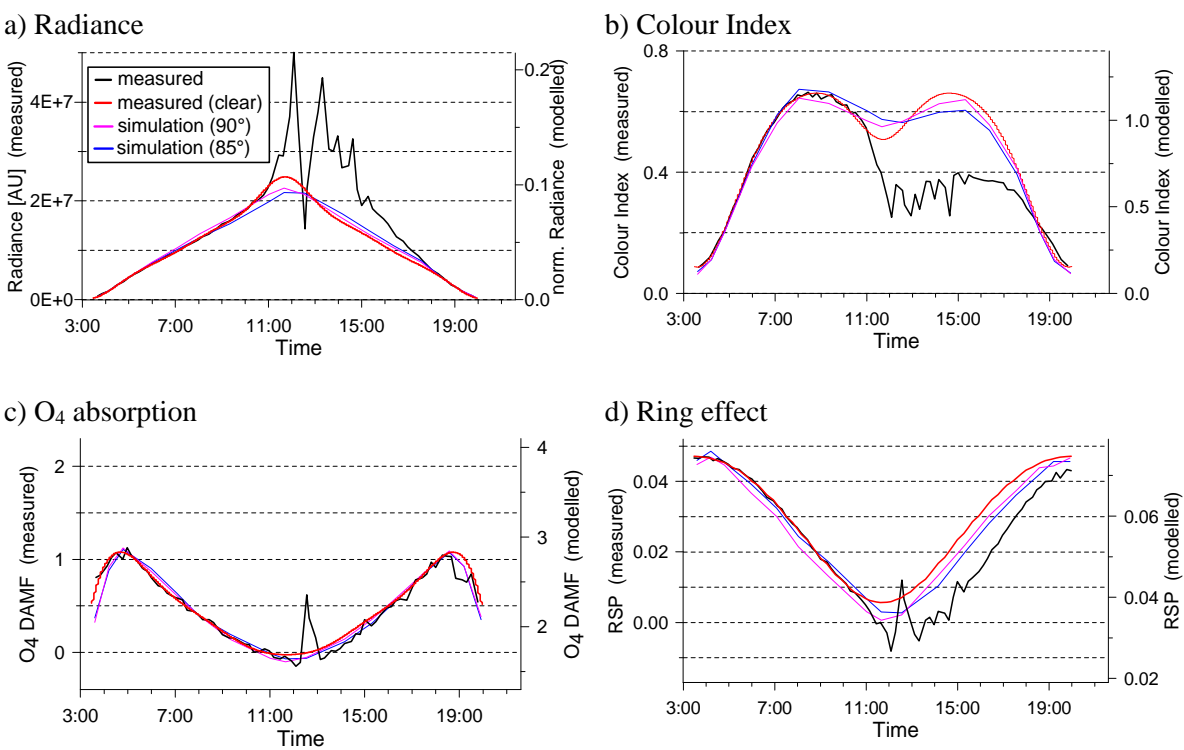

Fig. 7. Comparison of zenith measurements (black lines) with their respective clear-sky reference values (red lines) on 24 June 2009 (see also Fig. 1). Note that, instead of $90^{\circ}$, an elevation of $85^{\circ}$ was used, because the MAX-DOAS instrument was installed close to the Cabauw tower. Magenta lines $\left(90^{\circ}\right.$ elevation angle) and blue lines $\left(85^{\circ}\right.$ elevation angle) show results from radiative transfer simulations $(y$ axes at the right side) for an aerosol optical depth of 0.3 at $360 \mathrm{~nm}$ (see text). The red lines are polynomial fits to the clear-sky measurements before 10:30 (time is given as UTC).
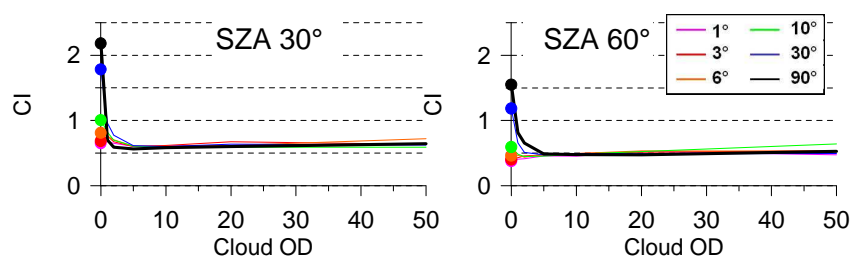

Fig. 8. Colour index (intensity ratio $320 \mathrm{~nm} / 440 \mathrm{~nm}$ ) as function of the cloud optical depth for various elevation angles (see legend) derived from radiative transfer simulations. The filled circles show values for a clear sky. Note that the simulations include ozone absorption for an $\mathrm{O}_{3}$ vertical column density (VCD) of $380 \mathrm{DU}$. The relative azimuth angle is $90^{\circ}$. Cloud properties are the same as for the results shown in Fig. 6.

with $\beta=E(440 \mathrm{~nm}) / E(320 \mathrm{~nm})$ being the proportionality constant and $E(\lambda)$ the combined efficiency of the grating, the detector and all other optical components of the instrument at wavelength $\lambda$ (while the efficiency of the grating and the detector might be available from the specifications provided by the manufacturer, the efficiency of the whole instrument is usually not well known).

Because of the strong wavelength dependence of Rayleigh scattering, the CI defined in Eqs. (2) and (3) typically shows high values for cloud-free situations, especially for measurements at high elevation angles (Fig. 8). Because of the much weaker wavelength dependence of scattering on cloud particles, the CI decreases in the presence of clouds. Thus, from deviations of the $\mathrm{CI}$ from the clear-sky values, the presence of clouds (with optical depths larger than about 3 to 5; see Fig. 8) can be easily deduced. Interestingly, for cloud optical depths larger than about 3 to 5 (the exact thresholds depend on SZA and relative azimuth angle) the CI for measurements at all elevation angles become very similar. With further increasing cloud optical depths, the CIs stays almost constant (usually a slight increase is found).

These general dependencies of the CI are also found in the measurements: with a clear sky (e.g. during the morning of 24 June 2009; see Fig. 1), high values of the CI are observed, especially for high elevation angles. In the presence of clouds (during noon on 24 June 2009, see Fig. 1, and on 15 June 2009, see Fig. 2) the CI shows smaller values, especially for the high elevation angles. The $\mathrm{CI}$ for all elevation angles become very similar if clouds are present.

In Fig. 7b the CI on 24 June 2009 for zenith view are shown (black line), together with the clear-sky reference values. Like for the radiance, a polynomial fit to the morning measurements of 24 June 2009 and results from radiative transfer simulations are presented as coloured lines. Again, the CIs for elevation angles of $85^{\circ}$ and $90^{\circ}$ differ slightly, with smaller CI values for $85^{\circ}$ in the afternoon. Like for radiance, a proportionality constant (see Eq. 4) can be determined by comparing the radiative transfer results to the clearsky measurements during the morning of 24 June 2009: we derive a value of about 1.75 .

The strong dependence of the CI on scattering (Fig. 8) by cloud particles makes it an ideal indicator for their presence: especially for measurements at high elevation angles, the CI 

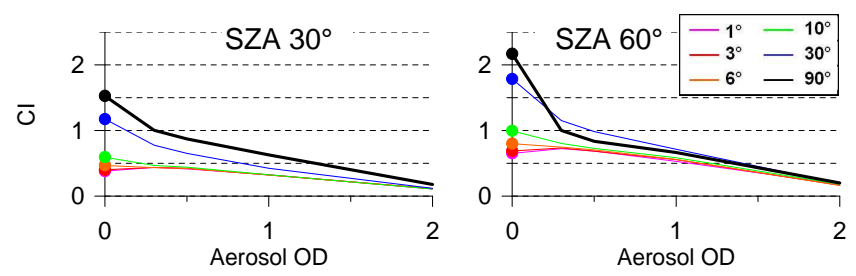

Fig. 9. Colour index (intensity ratio $320 \mathrm{~nm} / 440 \mathrm{~nm}$ ) as function of the aerosol optical depth for various elevation angles (see legend) derived from radiative transfer simulations (aerosol layer: $0-1 \mathrm{~km}$, asymmetry parameter AP: 0.68 , single scattering albedo SSA: 0.95 , Angström parameter: 1 , relative azimuth angle: $90^{\circ}$ ). Note that the simulations include ozone absorption for an $\mathrm{O}_{3} \mathrm{VCD}$ of $380 \mathrm{DU}$. The filled circles show values for clear sky.

typically decrease by more than a factor of two in the presence of clouds compared to clear-sky conditions. However, if CI measurements are used for cloud detection, one important aspect has to be considered: in the presence of strong aerosol loads, the CI can also be substantially reduced; see Fig. 9. However, for small and moderate AODs $($ AOD $<1)$, the reduction of the $\mathrm{CI}$ is smaller than for "typical" clouds (with optical depths $>3$ ). Another interesting finding is that for aerosol OD $<1$, a spread of CI values is found for the different elevation angles. The magnitude of this spread depends on the AOD and the viewing direction. In contrast, in the presence of clouds, the CIs for the different elevation angles usually become almost the same. These findings are also confirmed by measurements: in Fig. 3 MAX-DOAS CI for a mostly clear day with high AOD (close to unity for $360 \mathrm{~nm}$ ) are shown. Compared to the clear day with low aerosol load (Fig. 1) the CIs for zenith view are reduced, but still slightly higher than for a totally overcast day (15 June 2009; see Fig. 2). Even in the presence of a high aerosol load, the CI values for the different elevation angles are still systematically different, whereas for the cloudy day, they show almost the same values. Thus, from the spread of the CI values it is possible to distinguish the effect of typical clouds (OD > about 3) from that of weak or moderate aerosol loads (AOD < about 1). For measurements at high AOD (larger than about 1.5), the distinction becomes more difficult. In such cases, the investigation of the temporal variation of the derived quantities can yield additional information (see Sect. 3.5).

In this study, we chose $320 \mathrm{~nm}$ and $440 \mathrm{~nm}$ for the calculation of the CI. This choice was made in order to have a large spectral contrast within the wavelength range of our instrument and thus a good signal-to-noise ratio. Depending on the properties of other instruments, different wavelengths might be chosen for the calculation of the CI, especially including longer wavelengths (see also Gielen et al., 2013). While radiative transfer simulations indicate that the basic dependencies of the CI on cloud properties are similar for CI calculated at other wavelengths, the absolute $\mathrm{CI}$ values will of course be different compared to those in our study (they also depend on the wavelength dependence of the instrument's efficiency). It should be noted that if, like in our study, wavelengths with strong ozone absorption are used, the ozone absorption also has to be included in the radiative transfer simulations.

\section{3 $\mathrm{O}_{4}$ absorption}

The concentration of the oxygen $\operatorname{dimer}\left(\mathrm{O}_{4}\right)$ is proportional to the square of the $\mathrm{O}_{2}$ concentration (Greenblatt et al., 1990). It only varies slightly (according to changes of atmospheric pressure and temperature) and thus measurements of the atmospheric $\mathrm{O}_{4}$ absorption can be used to identify and quantify changes of the atmospheric radiation transport (Erle et al., 1995; Wagner et al., 1998; Winterrath et al., 1999).

Depending on the cloud properties and the viewing geometry, clouds can either increase or decrease the observed $\mathrm{O}_{4}$ absorption compared to clear-sky conditions: optically thin clouds at high altitude tend to decrease the $\mathrm{O}_{4}$ absorption for measurements at high elevation angle and to increase the $\mathrm{O}_{4}$ absorption at low elevation angles (Wagner et al., 2011). Optically thin clouds at low altitude typically tend to decrease the $\mathrm{O}_{4}$ absorption at all elevation angles. Vertically extended and optically thick clouds can lead to a strong increase of the $\mathrm{O}_{4}$ absorption (measured at all elevation angles) due to extended light path lengths inside the cloud (or between cloud layers) caused by multiple scattering (Erle et al., 1995). The different dependencies can be well reproduced by radiative transfer simulations (see Fig. 10). Note that extended light paths not only occur for geometrically and optically thick clouds, but can also be caused by "reflection" between a cloud layer and fog or snow at the surface.

In Fig. 10 the $\mathrm{O}_{4}$ absorption is expressed as air mass factor (AMF) (Solomon et al., 1987), which is the direct output of the radiative transfer simulations. From the measurements, $\mathrm{O}_{4}$ AMF can be calculated by dividing the $\mathrm{O}_{4}$ slant column density (SCD) by the $\mathrm{O}_{4}$ vertical column density (VCD):

$\mathrm{AMF}=\frac{\mathrm{SCD}}{\mathrm{VCD}}$.

Here, the SCD represents the concentration integrated along the light paths and the VCD represents the vertically integrated concentration. For the measurements at Cabauw, $\mathrm{a} \mathrm{O}_{4} \mathrm{VCD}$ of $1.41 \times 10^{43}$ molecules $^{2} \mathrm{~cm}^{-5}$ is used for the conversion of the $\mathrm{O}_{4} \mathrm{SCD}$ into $\mathrm{O}_{4}$ AMF calculated according to average surface pressure and temperature for 24 June 2009 (Piters et al., 2012) (for the units, see Greenblatt et al., 1990).

Note that in the DOAS analysis a second measurement has to be used (a so-called Fraunhofer reference spectrum) to correct for the strong Fraunhofer lines in the measured spectrum. Since the Fraunhofer reference spectrum also contains atmospheric $\mathrm{O}_{4}$ absorptions, the result of the DOAS analysis does not represent the absolute $\mathrm{O}_{4} \mathrm{SCD}$, but the difference between the $\mathrm{O}_{4} \mathrm{SCDs}$ of both measurements. This difference is 

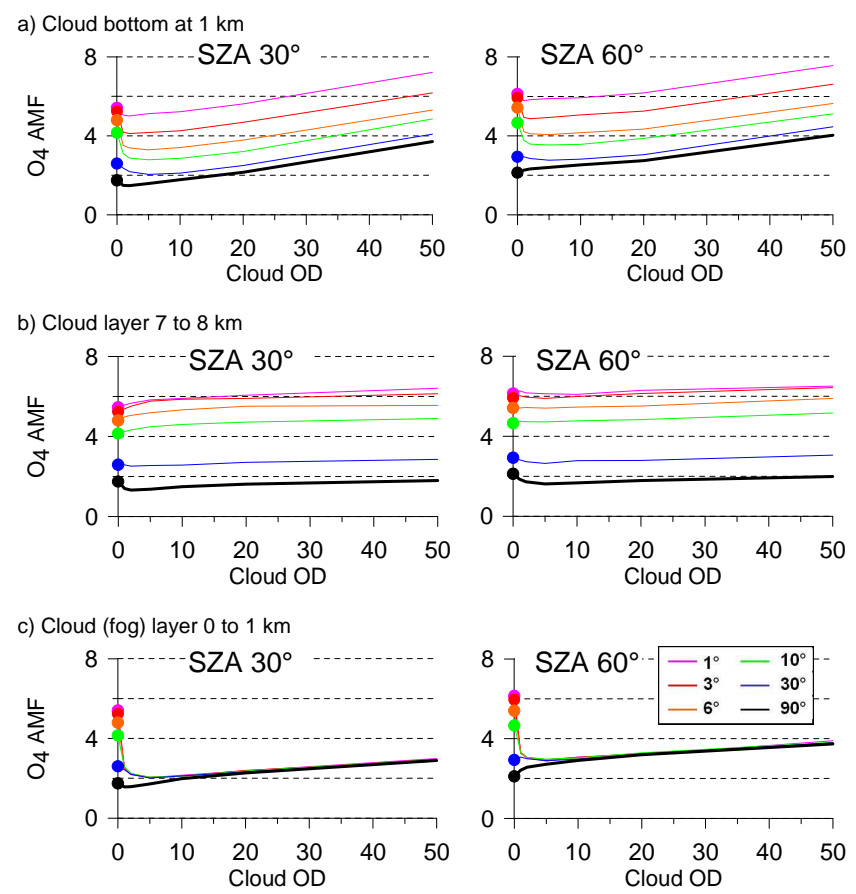

Fig. 10. $\mathrm{O}_{4}$ AMF at $360 \mathrm{~nm}$ as function of the cloud optical depth for different cloud altitudes derived from radiative transfer simulations. The cloud optical properties and relative azimuth angle are as in Fig. 6. (a) Low clouds as in Fig. 6; (b) high cloud between 7 and $8 \mathrm{~km}$; (c) cloud layer (fog) from the surface to $1 \mathrm{~km}$. The filled circles show values for a clear sky.

usually referred to as differential $\mathrm{O}_{4} \mathrm{SCD}$ (or $\mathrm{O}_{4} \mathrm{DSCD}$ ). For the $\mathrm{O}_{4}$ analysis we used a fixed Fraunhofer reference spectrum (from 24 June 2009, 11:36 UTC) measured in zenith direction.

The conversion of the $\mathrm{O}_{4}$ DSCD into an $\mathrm{O}_{4}$ differential air mass factor (DAMF) is performed similarly to Eq. (5):

$\mathrm{DAMF}=\frac{\mathrm{DSCD}}{\mathrm{VCD}}$

Thus, for the comparison of the measured $\mathrm{O}_{4}$ DAMFs, a constant value (the $\mathrm{O}_{4}$ AMF of the Fraunhofer reference spectrum) has to be subtracted from the simulated $\mathrm{O}_{4}$ AMFs. The $\mathrm{O}_{4}$ AMF of the Fraunhofer reference spectrum is at first unknown, but it is possible to estimate it from the comparison of the measured $\mathrm{O}_{4}$ DAMFs with the simulated $\mathrm{O}_{4}$ AMFs (e.g. Fig. 7c). For our measurements we estimate an $\mathrm{O}_{4}$ AMF of 1.7 (corresponding to an $\mathrm{O}_{4} \mathrm{SCD}$ of $2.4 \times 10^{43}$ molecules ${ }^{2} \mathrm{~cm}^{-5}$ ). It should also be noted that in contrast to some previous studies (Wagner et al., 2011; Clémer et a., 2010), no scaling factor for the $\mathrm{O}_{4}$ SCDs was applied in this study, because measurements and model results could be brought into agreement well without a scaling factor (also for the observation at low elevation angles). Currently we have no explanation for this finding.

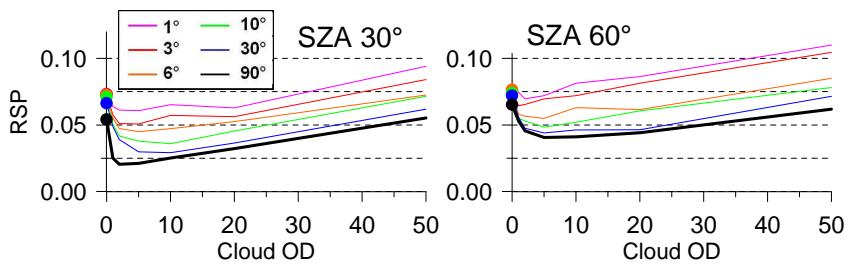

Fig. 11. Strength of the Ring effect (expressed as Raman scattering probability, RSP) at $360 \mathrm{~nm}$ as function of the cloud optical depth for various elevation angles (see legend) derived from radiative transfer simulations. The filled circles show values for a clear sky. Cloud properties are the same as for the results shown in Fig. 6.

In Fig. 1 the $\mathrm{O}_{4}$ DAMFs measured during a mostly clear day with low aerosol optical depth (24 June 2009) are shown. As expected, high values are found for measurements at low elevation angles. In Fig. 7 the $\mathrm{O}_{4}$ absorptions for zenith direction of that day is compared to different clear-sky reference values. Except for a small period during noon, the measurements are close to the clear-sky reference values, even during the occurrence of some thin clouds during the afternoon. This indicates a general "robustness" of the $\mathrm{O}_{4}$ absorption with respect to the influence of some kinds of clouds, especially for high and optically thin clouds. Such a robustness explains that in many cases even in the presence of clouds the inversion of tropospheric profiles from MAX-DOAS observations is possible (although with larger errors). Of course, the cloud influence can become much stronger, especially for low cloud altitudes, large optical depth and for broken clouds.

Similar results are found for another clear day (2 July 2009; see Fig. 3). However, in contrast to 24 June 2009, the aerosol optical depth on this day is much larger (about 1.0 compared to $0.2-0.6$ ). The increased aerosol optical depth leads to a smaller spread of the $\mathrm{O}_{4}$ DAMFs for the different elevation angles (as a result of the reduced atmospheric visibility), and the $\mathrm{O}_{4}$ DAMF for zenith view also shows a slightly stronger diurnal variation.

For mainly overcast days (e.g. Figs. 2 and 4) the spread of the $\mathrm{O}_{4}$ DAMFs for the different elevation angles is usually reduced compared to clear days. For zenith observations, enhanced values are often found compared to clear-sky conditions indicating the effect of multiple scattering inside the clouds (e.g. around noon on 15 June 2009). A related phenomenon was observed on the morning of 28 June 2009 (Fig. 4) when a persistent fog layer was present. During that period, continuously enhanced $\mathrm{O}_{4}$ DAMFs are found. In addition to light path enhancements caused by multiple scattering inside the fog layer, "reflection" between the fog layer and the cloud layer above has probably also contributed to the enhancement (after the fog disappeared a cloud layer above could seen). 
Another interesting finding is that during the presence of the fog in the morning the $\mathrm{O}_{4}$ DAMFs for all elevation angles are almost the same. This indicates that the direct light paths along the lines of sight were very short (and similar) for all elevation angles. This finding is in good agreement with the radiative transfer simulations shown in Fig. 10c. Note that during the periods of the largest increase of the $\mathrm{O}_{4}$ absorption at zenith view the observed radiance at zenith was systematically smaller than for clear-sky conditions (Figs. 2 and 4), also indicating optically thick clouds.

In this study we investigate the $\mathrm{O}_{4}$ absorption band at $360 \mathrm{~nm}$ (note that in the spectral analysis we also include the weaker absorption band at $380 \mathrm{~nm}$ ). Thus, our results are representative only for the effects of clouds in the selected UV spectral range. If $\mathrm{O}_{4}$ absorption bands at larger wavelengths are analysed (e.g. at 477,577 or $630 \mathrm{~nm}$ ), the basic effects of clouds are expected to be similar. However, especially for observations at low elevation angles the light paths below the clouds might systematically be larger than in the UV.

\subsection{Ring effect}

Inelastic scattering due to rotational Raman scattering on atmospheric molecules (about $2 \%$ to $4 \%$ of all molecular scattering events) leads to a filling-in of Fraunhofer lines in spectra of scattered sunlight (Grainger and Ring, 1962; Kattawar et al., 1981). The strength of this so-called Ring effect can be retrieved from MAX-DOAS spectra by including a so-called Ring spectrum in the DOAS analysis (Solomon et al., 1987). The fit coefficient of the Ring spectrum is proportional to the so-called RSP (see Wagner et al., 2009), which can be directly compared to results from radiative transfer simulations.

In the presence of clouds, the relative contribution of inelastically scattered light usually decreases compared to clear-sky conditions, because the additional scattering on cloud particles is an elastic process. This effect explains the decrease of the Ring effect with increasing OD for low OD (Fig. 11). In contrast to the $\mathrm{O}_{4}$ absorption, the strength of the Ring effect depends strongly on the scattering angle and less on the light path length. But for large cloud OD, strongly enhanced light paths inside clouds can also strongly increase the probability of additional scattering on molecules and thus increase the strength of the Ring effect (Fig. 11).

In Fig. 1 the strength of the Ring effect (expressed as RSP) measured on a mostly clear day (24 June 2009) with low aerosol optical depth is shown. For most parts of this day similar values of the RSP are found for the different elevation angles (except zenith view). This confirms the rather weak dependence of the Ring effect on the atmospheric light path length. Since the Ring effect depends on the relative azimuth angle, the spread of the RSP for different elevation angles is different for different times of the day, especially during sunrise and sunset.
In Fig. 7d the RSP for zenith direction is compared to different clear-sky reference values. During the morning good agreement of the measured RSP with the clear-sky reference values is found, but during the afternoon systematic differences occur (around noon, deviations are caused by the presence of clouds). These deviations can be mainly attributed to the increased AOD (aerosol scattering also contributes to elastically scattered light), but the deviation of the viewing angle from exactly zenith also causes a small reduction of the RSP.

For mainly overcast days (Figs. 2 and 4) the RSPs for all elevation angles become similar. And like for $\mathrm{O}_{4}$ in the presence of fog (morning of 28 June 2009; see Fig. 4) the RSP is almost identical for all elevation angles indicating very short (and similar) light paths. At noon on 15 June 2009 (Fig. 2) the Ring effect (especially for zenith view) is largely increased compared to the clear-sky reference values, indicating strong light path enhancements inside the clouds due to multiple scattering (similar to the $\mathrm{O}_{4}$ absorption). This finding is also in good agreement with the radiative transfer simulations shown in Fig. 11.

\subsection{Temporal variability}

An unambiguous discrimination between clear- and cloudysky conditions is not possible for all of the quantities discussed above. For example, the measured radiance, the $\mathrm{O}_{4}$ absorption and the Ring effect can be both increased and/or decreased in the presence of clouds. Fortunately, the influence of clouds on the CI is unambiguous: compared to clearsky conditions, the $\mathrm{CI}$ for zenith view is always decreased in the presence of clouds (typically by more than a factor of two for cloud optical depths $>3$ ). However, as demonstrated in Sect. 3.2, high aerosol loads can also lead to a similar decrease of the CI (although the effect of typical aerosol loads on the CI is usually smaller than that of clouds). Thus, additional information should be used to unambiguously detect the presence of clouds.

It was demonstrated using the examples shown in the previous sections that the variation of the retrieved quantities between two measurements (at the same elevation angle) is often larger by far than the temporal changes in clear-sky conditions (compare, e.g., the results shown in Figs. 2 and 4 with those shown in Figs. 1 and 3). Even for measurements under a totally overcast sky, a strong temporal variability of the derived quantities is usually observed. These variations are caused by changes in the cloud properties (e.g. the cloud optical depth or the cloud altitude).

In Fig. 5 results for a day with broken clouds (on the morning of 28 June 2009) are shown. As expected, for measurements under broken clouds, the temporal variation of the retrieved quantities is rather strong. The strongest and most rapid changes are typically observed in zenith direction, because the line of sight is perpendicular to the orientation of the cloud layer. To quantify temporal variations we define the 

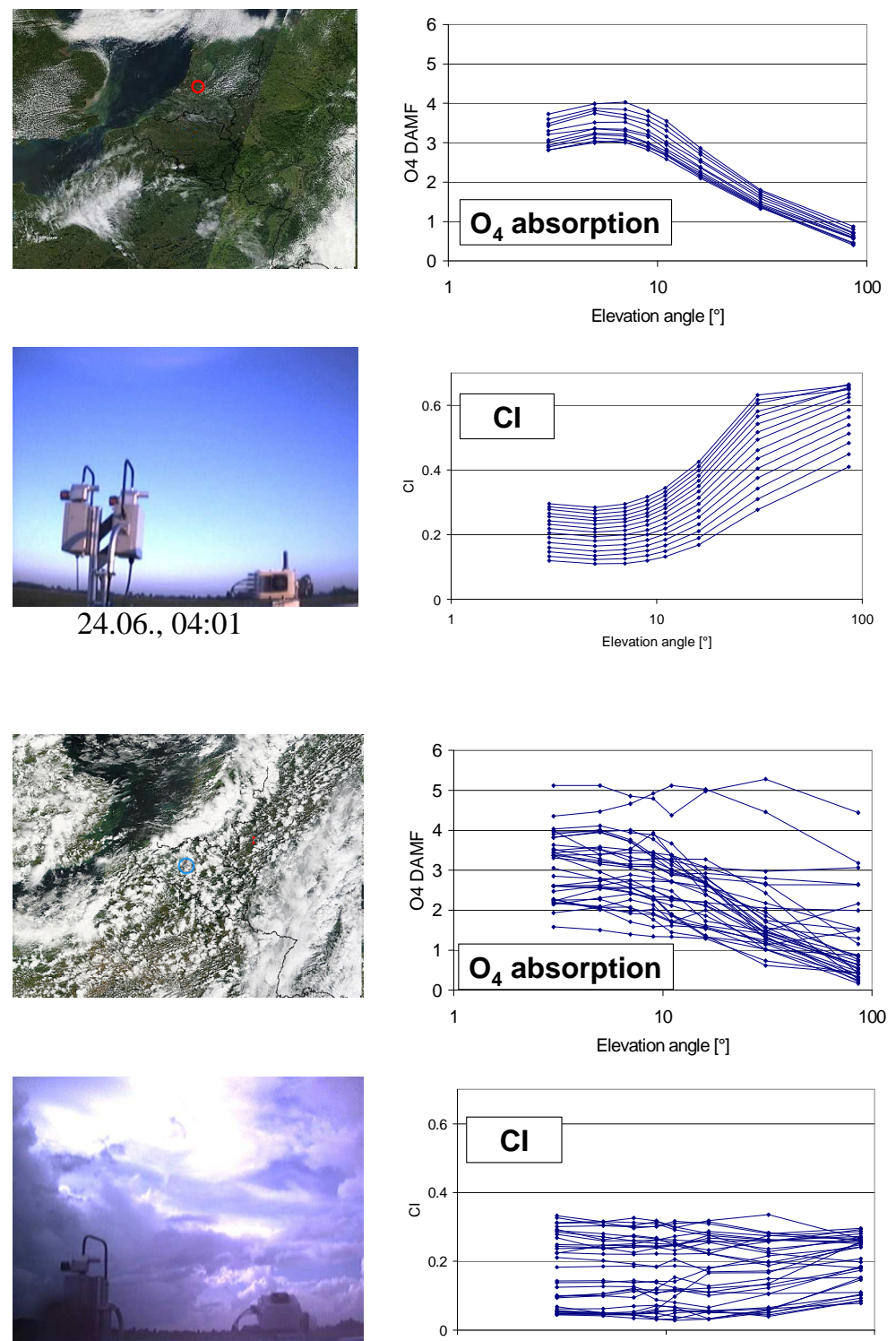

07.07., $15: 16$

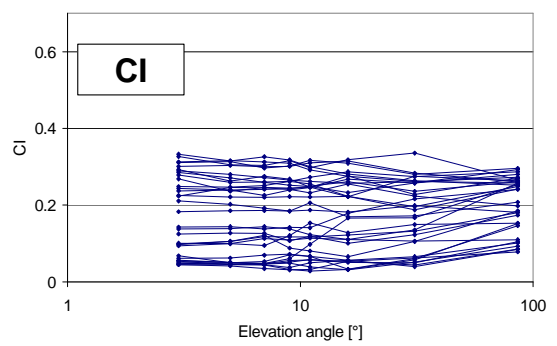

Fig. 12. Right-hand column: dependence of the $\mathrm{O}_{4}$ absorption and the $\mathrm{CI}$ on the elevation angle for measurements in clear (24 June 2009 ; top) and cloudy (7 July 2009; bottom) conditions. The images on the left show images taken from satellite and the ground for the selected days. Note that the maximum elevation angle is $86^{\circ}$.

so-called temporal smoothness indicator (TSI), the discrete approximation of the second derivative in time:

$\operatorname{TSI}_{y, n}=2 \cdot\left[\frac{\Delta t_{1} y_{n+1}+\Delta t_{2} y_{n-1}}{\Delta t_{1} \Delta t_{2} \cdot\left(\Delta t_{1}+\Delta t_{2}\right)}-\frac{y_{n}}{\Delta t_{1} \Delta t_{2}}\right]$.

Here, $y$ indicates the considered quantity (e.g. the CI), and $\mathrm{n}$ indicates a selected elevation sequence. $\Delta t_{1}$ and $\Delta t_{2}$ are the time steps between measurement sequences $n-1$ and $n+1$, respectively. Equation (7) ensures that smooth systematic variations of the observed quantity, e.g. caused by the variation of the SZA, lead to small values of the TSI, while rapid variations between consecutive elevation sequences (as caused by clouds) lead to large TSI. In the case of temporal gaps $(\Delta t>30 \mathrm{~min})$, no TSI is calculated. The unit of TSI is the unit of $y$ divided by the time squared.

\subsection{Dependence on elevation angle}

Observations at different elevation angles probe different parts of the sky. Thus, in the presence of spatially heterogenous clouds, the retrieved quantities for neighbouring elevation angles are usually different. In Fig. 12 the dependence of the $\mathrm{O}_{4}$ DAMF and the $\mathrm{CI}$ for measurements in clear and cloudy conditions are shown as examples. Under a clear sky, 
the observed quantities depend smoothly on the elevation angle (similar results are found for the radiance and the Ring effect). In contrast, in cloudy conditions, a nonsmooth dependence is found. In extreme cases (e.g. in the presence of broken clouds) at some elevation angles cloudy parts and at others clear parts of the sky might be observed. Thus, from the investigation of the smoothness of the elevation angle dependency, information about the presence of clouds during that elevation sequence can be obtained. For the quantification of the smoothness of the elevation angle dependence, the so-called elevation smoothness indicator ESI is defined:

$\operatorname{ESI}_{y, n}=\sqrt{\sum_{\alpha_{\min }}^{\alpha_{\max }}\left(y_{n, \alpha}-P_{n}(\alpha)\right)^{2}}$.

Here, $y$ indicates the considered quantity (e.g. the measured radiance or $\mathrm{CI}$ ) and $n$ indicates the selected elevation sequence. $\alpha$ indicates the elevation angle, and $P_{n}(\alpha)$ is a polynomial (of 3rd degree) fitted to $y_{n, \alpha} . \alpha_{\min }$ and $\alpha_{\max }$ define the range of elevation angles for which ESI is calculated. In this study we select $\alpha_{\min }=2^{\circ}$ and $\alpha_{\max }=15^{\circ}$. The limitation to this range is to some extent arbitrary, but ensures that the polynomial fit is performed to values with almost equidistant differences between the elevation angles. Including higher elevation angles could also complicate the calculation of the ESI, because for specific viewing geometries the measured quantities for higher elevation angles might be either higher or lower than the values derived at $15^{\circ}$. Thus, the limitation to elevation angles $\leq 15^{\circ}$ ensures that no inflexion point affects the polynomial fit. The unit of the ESI is the unit of $y$.

Note that for the measured radiance and CI, we normalise the calculated TSI and ESI (Eqs. 7 and 8) by division by the zenith clear-sky reference values (results from radiative transfer simulations; see Fig. 7).

In Fig. 13 TSI and ESI for two selected days are shown. The upper panel presents results for a mainly clear day (24 June 2009) and the lower panel for a day with broken clouds in the morning (18 June 2009). During the cloud-free morning of 24 June 2009, the TSI, in particular, shows very small values. Later on that day, and especially around noon, the TSI is enhanced, indicating the influence of changing cloud cover on the MAX-DOAS observations. Even higher values of the TSI are found for 18 June 2009, for which rapidly varying broken clouds were present. The highest values of the TSI are usually found for high elevation angles, especially for zenith view.

Large differences between both days are also found for the ESI. However, surprisingly, for completely clear-sky conditions slightly enhanced ESI are often found (e.g. for the $\mathrm{O}_{4}$ DAMF on the morning of 24 June 2009). Such small variations of the elevation dependencies of the $\mathrm{O}_{4}$ DAMFs are also seen in Fig. 12 (top). The reason for the enhanced ESI is not completely clear. One possibility might be local aerosol sources which affect individual elevation angles. On
18 June 2009 the ESI shows much higher values than on 24 June 2009 , indicating that broken clouds not only strongly affect the temporal variation of the measured quantities but also the smoothness of the elevation sequence dependence.

\section{Cloud classification scheme}

As shown in the previous sections, the presence of clouds can be deduced by different methods from MAX-DOAS measurements of the radiance, colour index, $\mathrm{O}_{4}$ absorption and Ring effect :

a. The measured quantities can be compared to their respective clear-sky reference values.

b. The temporal variation of the measured quantities can be investigated.

c. The dependence of the measured quantities on elevation angle can be investigated.

These three methods can in principle be applied to all measured quantities and all viewing directions. However, some quantities (e.g. the CI) and some elevation angles (e.g. zenith view) are especially well suited to the detection of clouds. In order to minimise the computational efforts, we propose a detailed cloud detection and classification algorithm based on the radiance, the $\mathrm{CI}$ and the $\mathrm{O}_{4}$ absorption; Fig. 14 shows a flow chart of this algorithm. Primary classification results are indicated by the black arrows. Only one primary classification result can be attributed to a given measurement (elevation sequence). Blue arrows indicate secondary classification results, which can be attributed in addition to the primary classification results. Note that Ring effect results are not considered, because they do not provide significant additional information.

The choice of the selected quantities (and threshold values; see below) in this study in our opinion constitutes a good compromise between effort and benefit. Depending on the required accuracy and the computational effort, only part of the proposed classification steps might be applied. If, e.g., only a distinction between clear and cloudy sky is required, the consideration of the $\mathrm{CI}$ in zenith direction $\mathrm{CI}_{\mathrm{Z}}$ might be sufficient (see, e.g., Gielen et al., 2013). In the following we describe the individual steps of the cloud classification algorithm (Fig. 14) in detail.

\subsection{Discrimination between a clear sky and clouds or high aerosol loads}

In the first step the measured CI values for zenith observations are considered. They are divided by the respective clear-sky values for the same SZA, yielding the normalised CI. In this study, we use clear-sky reference values from radiative transfer simulations (for an aerosol optical depth of 
24 June 2009
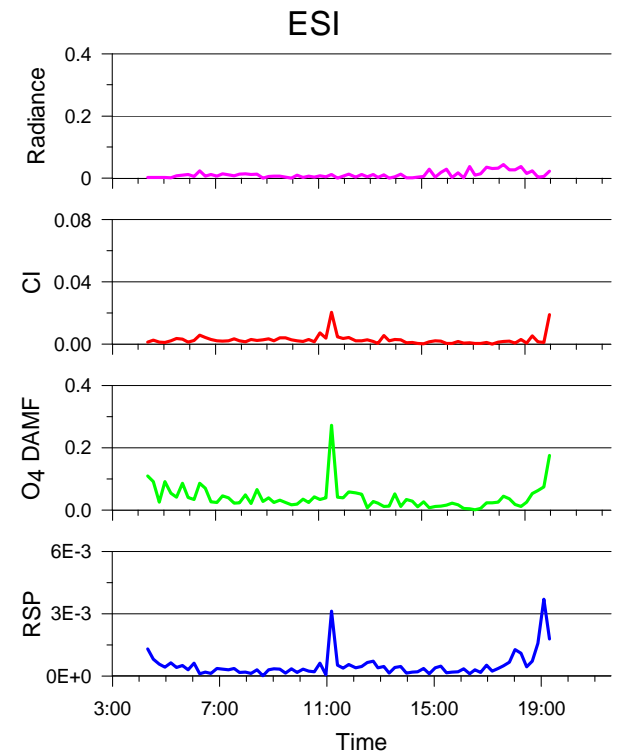

\section{June 2009}
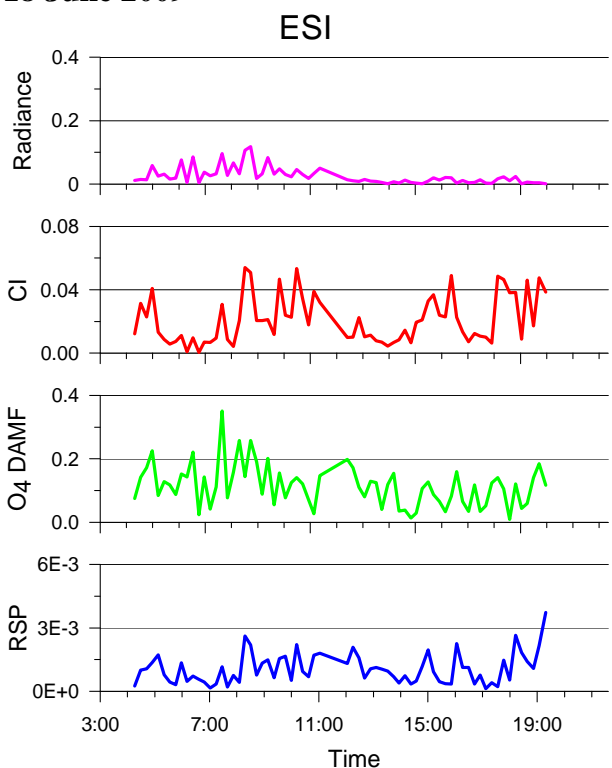
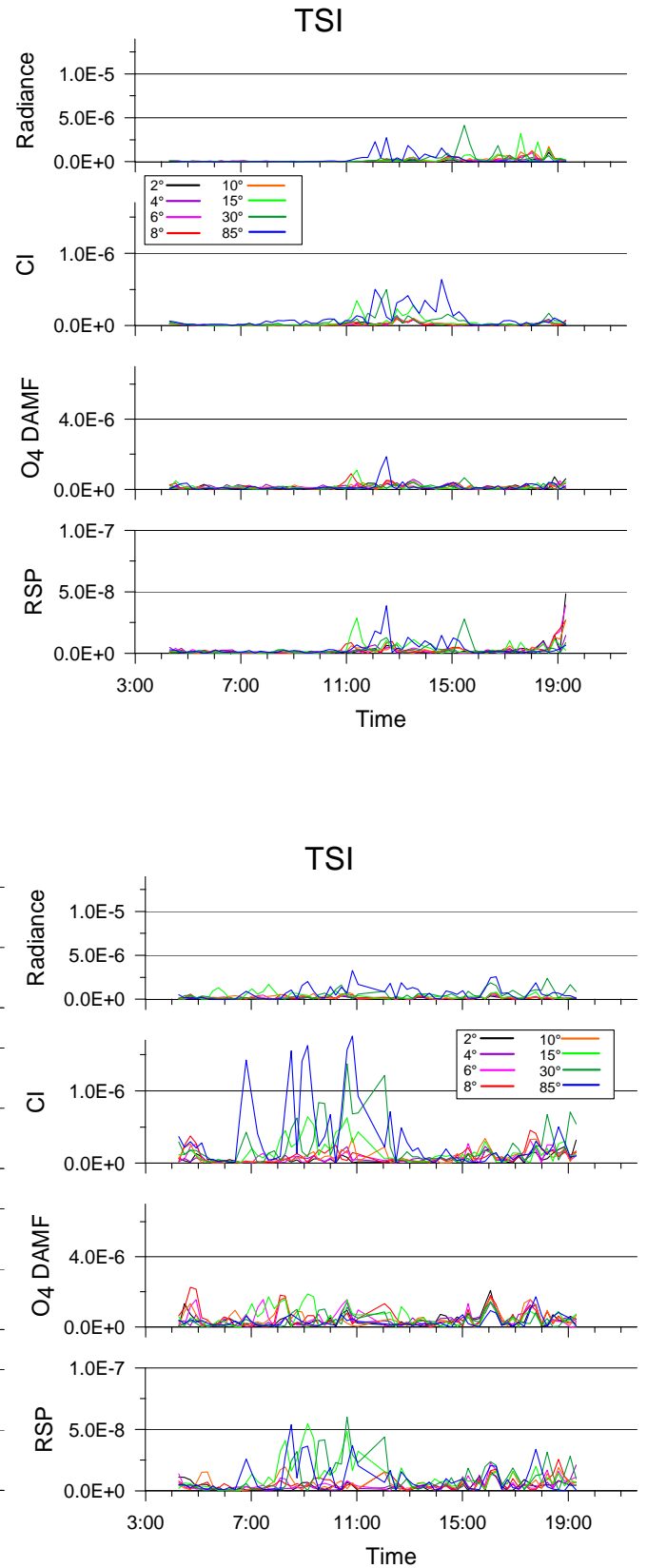

Fig. 13. Elevation smoothness indicator (ESI; left) and temporal smoothness indicator (TSI; right) for the different retrieved quantities (the units of the TSI are the units of the considered quantities divided by s ${ }^{2}$ ). In the upper panel, results for a mainly clear day (24 June 2009 ) and in the lower panel results for a day with broken clouds in the morning (18 June 2009) are shown (time is given as UTC).

0.3; see Sect. 3.1). If the normalised CI for zenith observations $\left(\mathrm{CI}_{\mathrm{Z}}\right)$ is smaller than a prescribed threshold value (Sect. 4.6), the measurement is classified as cloudy, or as affected by high AOD. Otherwise, the measurement is classified as made under a clear sky. In this prototype study, we use a constant threshold for the whole SZA range. However, it should be noted that for large SZA (about $>75^{\circ}$ ) the selected threshold value seems to be too low, leading to a systematic underestimation of the cloud-contaminated measurements (measurements with $\mathrm{SZA}>75^{\circ}$ constitute only a small fraction of all measurements, i.e. before about 05:40 and after 19:00 UTC). Future studies should apply a more sophisticated threshold depending on SZA. 
a)

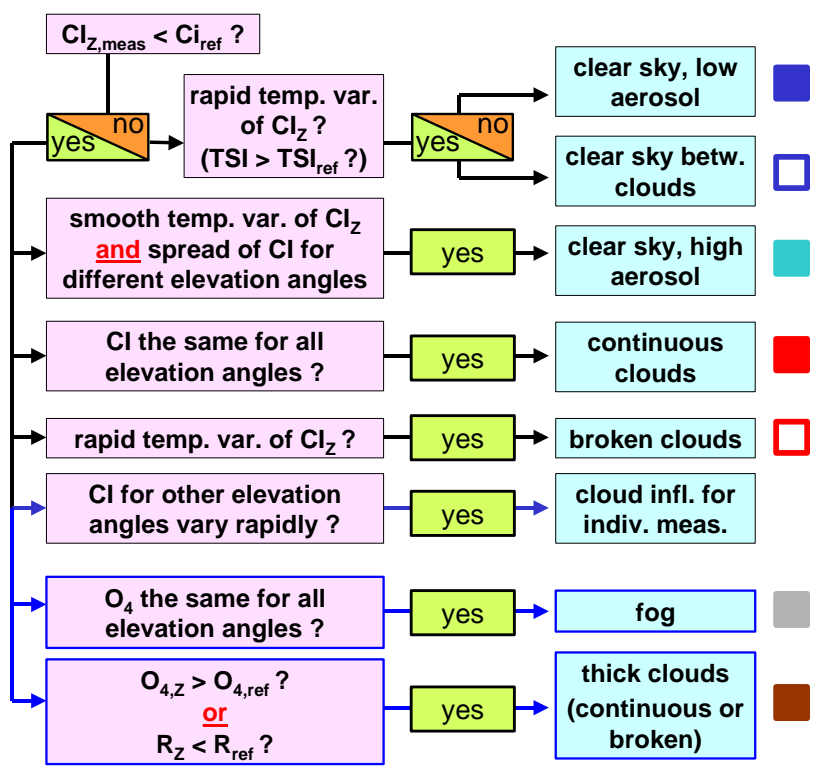

b)

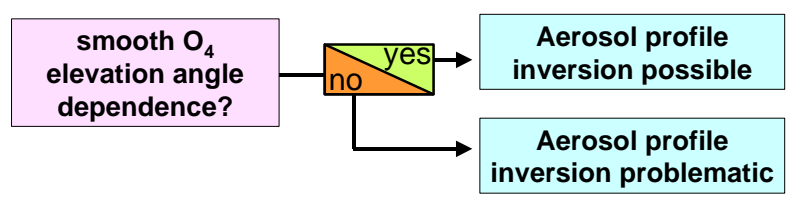

Fig. 14. (a) Cloud classification scheme suggested in this study. Paths with black arrows indicate the primary classification results: only one primary classification result can be attributed to a given elevation sequence. Paths with blue arrows indicate secondary classification results, which complement the primary classification results. (The symbols on the right side are the same as in Figs. 16 and 17). (b) Scheme to estimate the quality of the aerosol profile inversion.

\subsection{Discrimination between continuous clear sky and cloud holes}

For measurements identified in the first step as clear-sky measurements, it is important to know if they were made under completely clear skies or if the telescope was just pointing to an area of clear sky between clouds. The latter can be concluded if the $\mathrm{CI}_{\mathrm{Z}}$ shows rapid temporal variation, i.e. the TSI (see Sect. 3.5) is larger than a chosen threshold value (see Sect. 4.6).

\subsection{Discrimination between continuous clouds, broken clouds and high aerosol loads}

Usually (especially in the absence of strong local sources) the atmospheric aerosol load changes rather slowly with time. In contrast, cloud properties typically change rapidly (on the order of minutes), especially in the presence of broken clouds.
Thus, enhanced values of the temporal smoothness indicator TSI indicate the presence of broken clouds.

Low TSI (in cases of reduced $\mathrm{CI}_{Z}$ ) either indicate high aerosol loads or continuous cloud cover. To discriminate between both cases, the spread of the CI values for the different elevation angles can be investigated: continuous cloud cover can be identified by small differences between the maximum and minimum $\mathrm{CI}$ values for a chosen elevation sequence. If the spread of the CI for different elevation angles is above a chosen threshold (see Sect. 4.6), the measurement is classified as being affected by a high AOD.

\subsubsection{Identification of fog}

In the presence of fog, the atmospheric light paths and thus the $\mathrm{O}_{4}$ DAMF for all elevation angles become the same. Fog can thus be identified if the difference between the maximum and minimum $\mathrm{O}_{4}$ DAMF values for the whole elevation sequence falls below a prescribed threshold (see Sect. 4.6).

\subsubsection{Identification of thick clouds}

In the presence of optically thick clouds, the $\mathrm{O}_{4}$ DAMF can be significantly increased compared to the respective clearsky values (see Sect. 3.3 and Fig. 2). The measured radiance typically also falls below the clear-sky reference values (see Sect. 3.1 and Fig. 2). Thus, thresholds (see Sect. 4.6) for both quantities can be used to indicate the presence of optically thick clouds. Note that the thresholds are applied to normalised values: for the radiance, the measured values are divided by the clear-sky reference values; for $\mathrm{O}_{4}$ the clearsky reference values are subtracted from the measured $\mathrm{O}_{4}$ DAMF.

\subsection{Classification of the cloud influence for individual measurements}

Although the cloud influence for non-zenith viewing angles is usually weaker than for zenith observations, the temporal variability for the lower elevation angles can also provide useful information. In principle it is even possible to detect a potential cloud influence for an individual observation from the TSI of the specific elevation angle. In our algorithm we follow a simplified procedure: we calculate the sum of the TSI for all non-zenith elevation angles $\left(\mathrm{TSI}_{L}\right)$. Enhanced values of $\mathrm{TSI}_{L}$ can yield valuable information, especially in cases with low TSI for zenith viewing. In such cases, cloud holes are present in zenith view while cloud patches are present elsewhere.

\subsection{Elevation smoothness indicator for $\mathrm{O}_{4}$}

Interestingly, even in the presence of clouds (except for broken clouds), a smooth dependence of the $\mathrm{O}_{4}$ DAMF on elevation angle is often found. However, from this it can not simply be concluded that a meaningful inversion of aerosol 
a) 24 June 2009
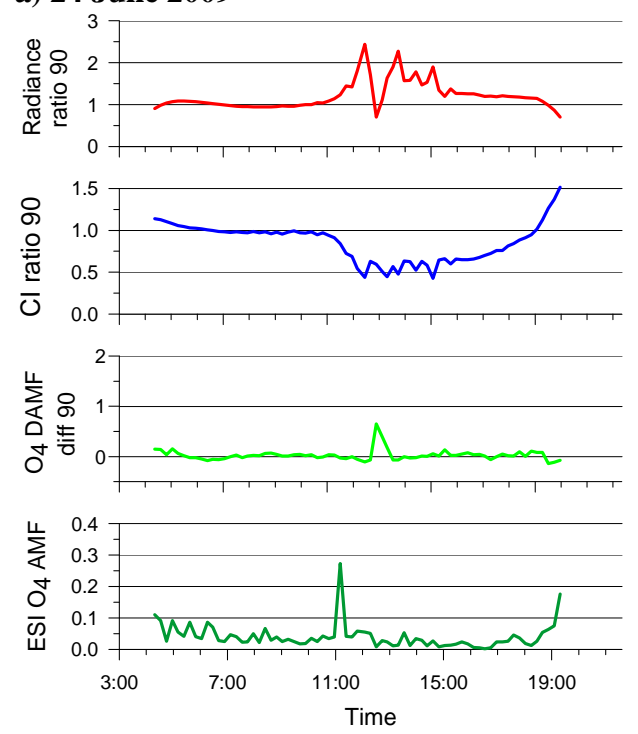

b) 15 June 2009
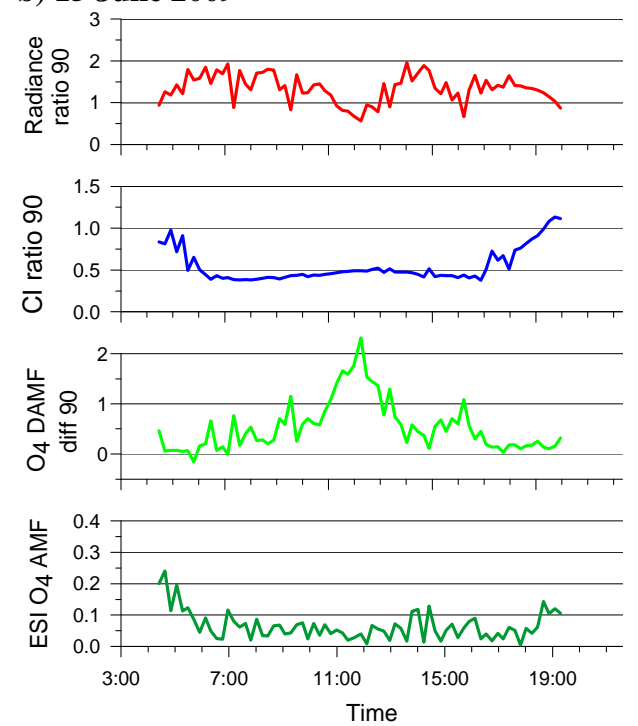
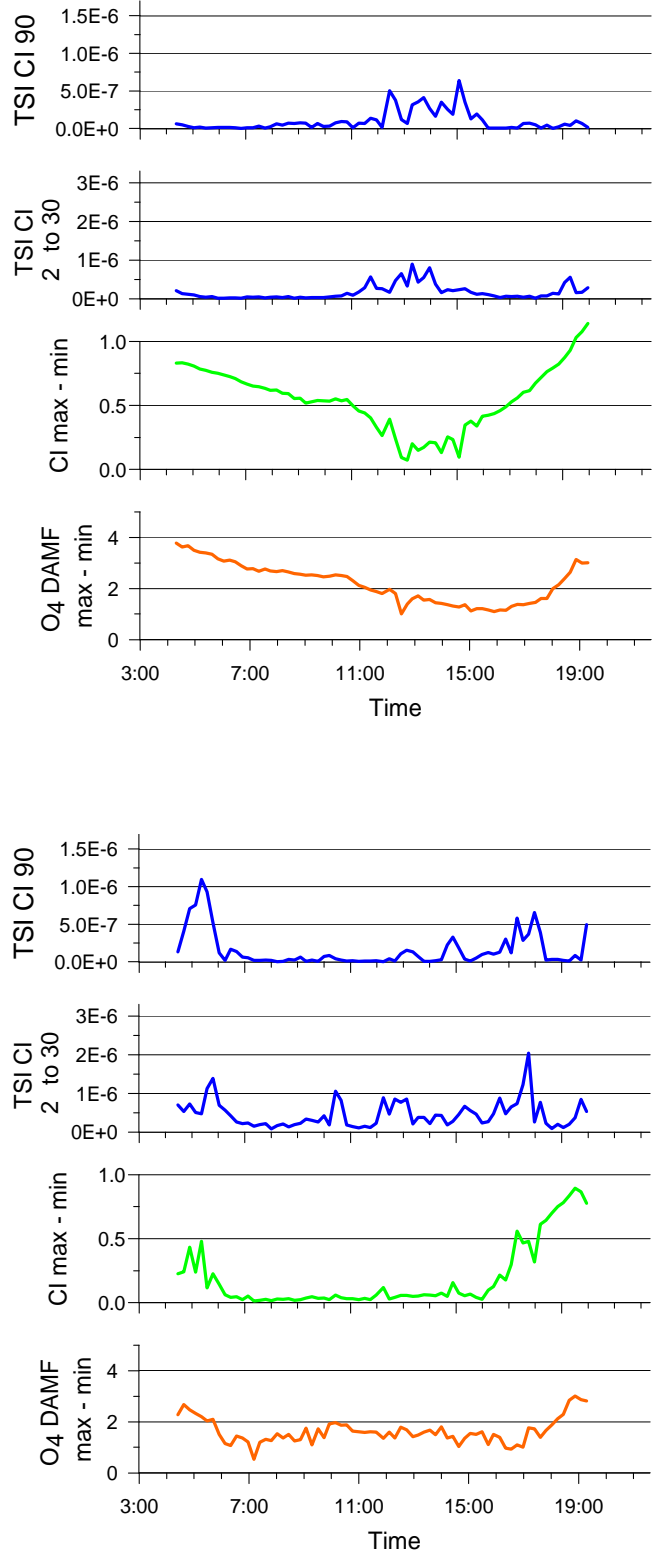

Fig. 15. Selected quantities for the identification and classification of clouds from MAX-DOAS observations (see Fig. 14) for the different selected days (see Table 1). The three upper panels of the left-hand column of each subfigure show the normalised radiance, $\mathrm{CI}$ and $\mathrm{O}_{4}$ DAMF for zenith view. The lower panel in the left-hand column shows the elevation smoothness indicator (ESI) for $\mathrm{O}_{4}$. The two top panels of the right-hand column of each subfigure show the temporal smoothness indicators (TSI) of the CI for zenith view and the sum of the TSI for all other elevation angles (units: $\mathrm{s}^{-2}$ ). The two bottom panels of the right-hand column show the difference between the maximum and minimum values of the $\mathrm{CI}$ and the $\mathrm{O}_{4}$ DAMF for all elevation angles (Time is given as UTC.)

profiles is possible. However, a nonsmooth dependence of the $\mathrm{O}_{4}$ DAMF on elevation angle can be used as a clear indication that a meaningful aerosol profile inversion is not possible. In such cases, the complete elevation sequence might be skipped for further processing. Alternatively, from a detailed inspection of all $\mathrm{O}_{4}$ DAMF of the selected elevation sequence, it might be possible to identify and remove "outliers", which are obviously affected by clouds. Based on the remaining measurements a meaningful aerosol profile inversion might then be possible (although with larger uncertainties). Similar procedures might also be used to assess and improve the quality of the trace gas profile inversions. 
c) 02 July 2009
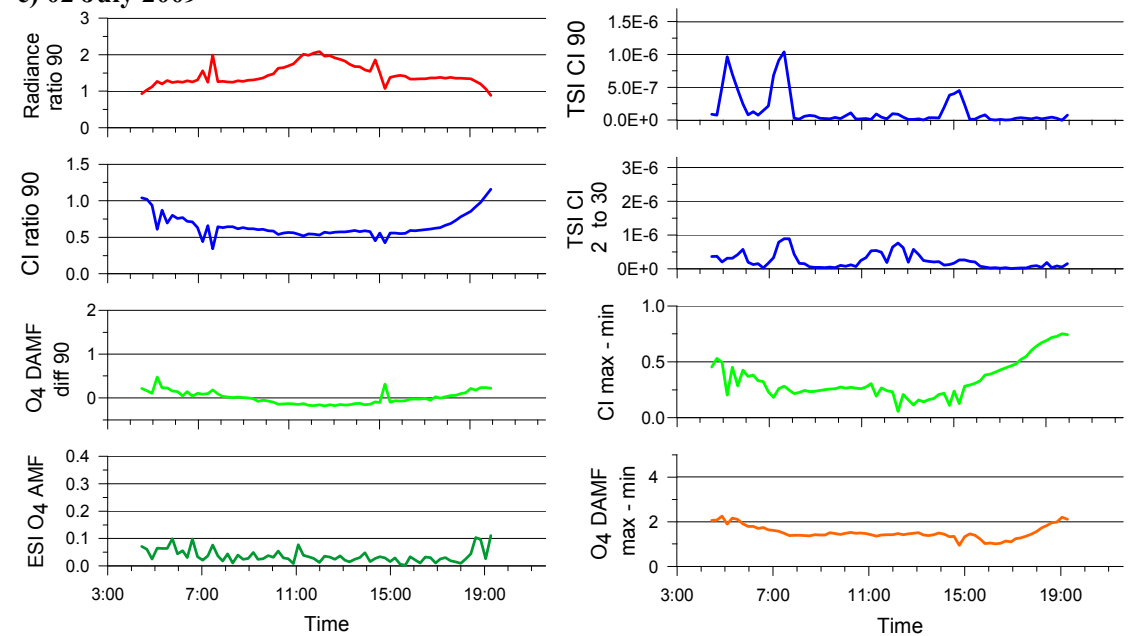

d) 28 June 2009
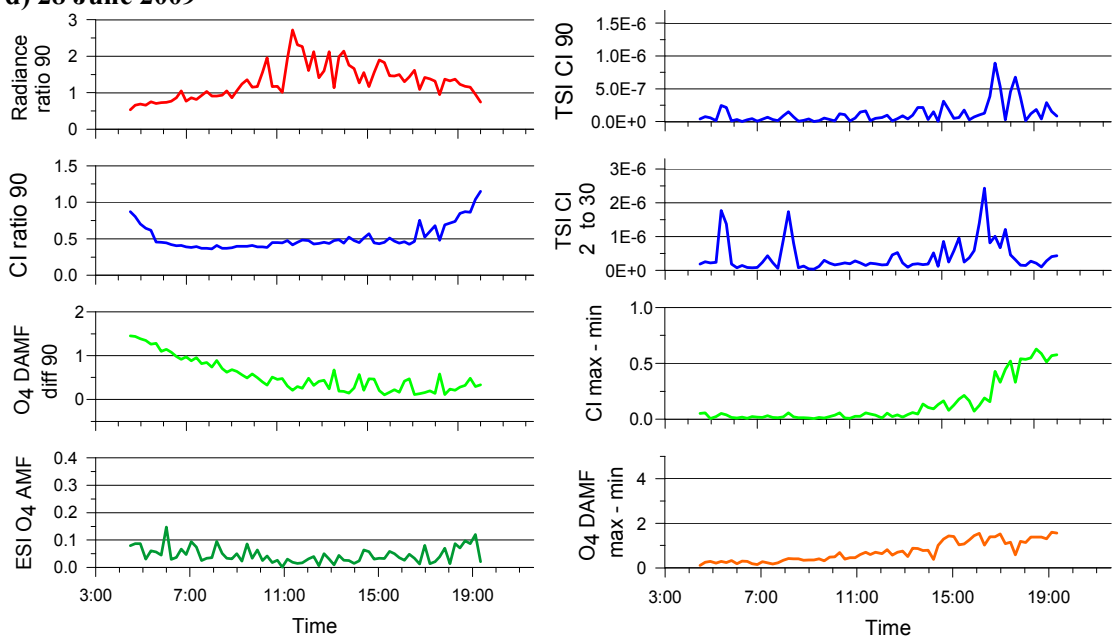

e) 18 June 2009
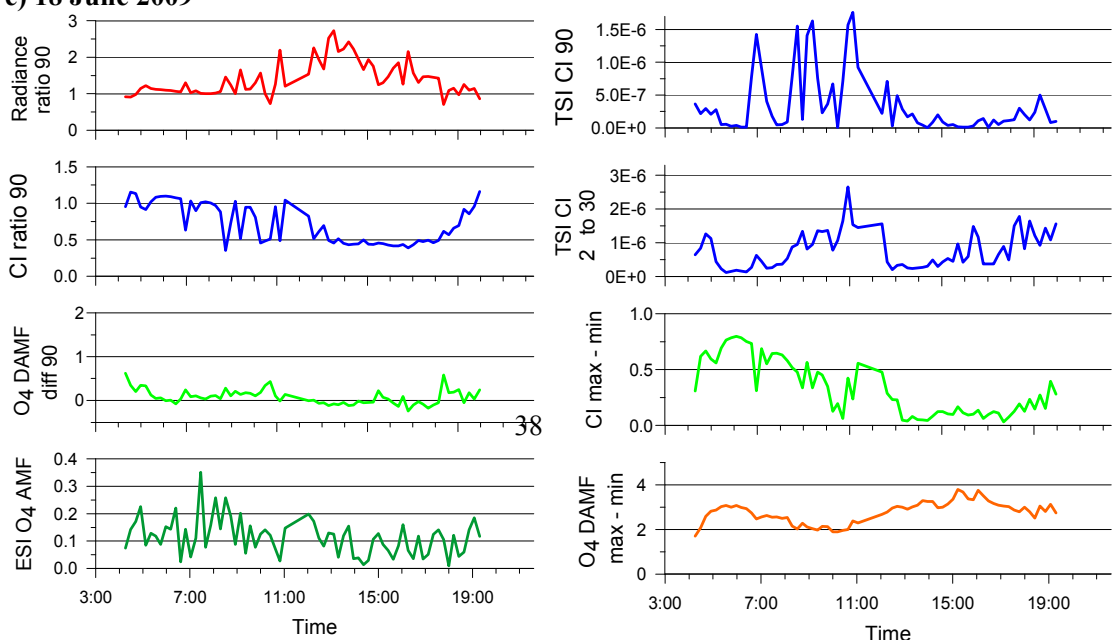

Fig. 15. Continued. 


\subsection{Selection of threshold values}

In Fig. 15 the quantities discussed in the previous section (see also Fig. 14) are shown for selected days (the same days as discussed in Sects. 3.1-3.4). In the three upper panels of the left-hand column of each subfigure, normalised measurements in zenith direction are shown (radiance, the CI and the $\mathrm{O}_{4}$ DAMF). In the lower panel of the left-hand column, the ESI for the $\mathrm{O}_{4}$ DAMF is shown. In the two upper panels of the right-hand column of each subfigure, the temporal smoothness indicator TSI for the CI is shown for either zenith direction or the sum of the TSI for all non-zenith directions. In the two lower panels of the right-hand column the difference between the maximum and minimum values of the $\mathrm{CI}$ and the $\mathrm{O}_{4}$ DAMF for a complete elevation sequence is shown. Based on these results for the selected days and by comparison to the corresponding cloud properties derived from images taken from satellite and the ground, we chose a set of threshold values for the various decisions to be made within our proposed cloud classification scheme (Fig. 14). The derived threshold values are summarised in Table 2.

\subsection{Results of the cloud classification scheme for the MAX-DOAS measurements during CINDI}

Figure 16 presents the results of the cloud classification scheme for 18 June 2009 with two different levels of complexity. In the upper part, only CI measurements in zenith direction are used. From such observations a clear sky (continuous or cloud holes) as well as cloudy skies (continuous or broken clouds) can be identified.

In the lower part of Fig. 16, the results from the complete classification scheme (Fig. 14) are presented; in addition to the simple scheme, more cases can be identified:

- For clear-sky observations, situations with low or high AOD are distinguished.

- For clear-sky observations, broken clouds before and after the selected elevation sequence can be identified not only for zenith view but also for low elevation angles.

- For cloudy-sky observations, the presence of thick clouds is indicated.

- For cloudy-sky observations, the presence of fog is indicated.

Figure 17 presents results of the complete cloud classification scheme for five selected days. In addition, images of the web camera at intervals of $30 \mathrm{~min}$ are also shown. The sky images are synchronised with the results of the cloud classification scheme (four images are always grouped in a vertical column with a "width" of $2 \mathrm{~h}$ ) to allow a direct comparison. For the selected days, very good agreement is found between the cloud classification scheme and the sky images. In particular, the following observations can be made:
Simple classification

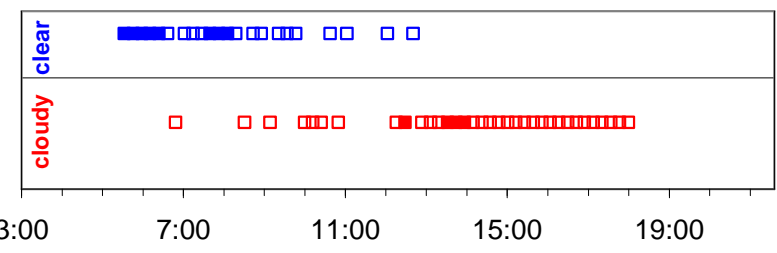

Detailed classification

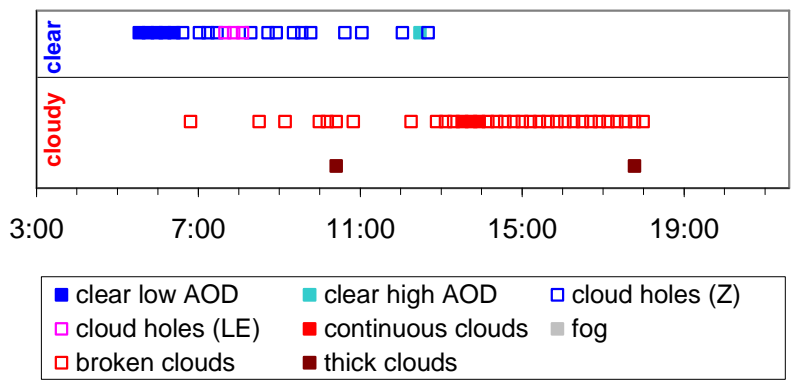

Fig. 16. Results of the cloud classification scheme for 18 June 2009. Top: discrimination between clear and cloudy skies (including cloud holes and broken clouds) using a simple version based on the $\mathrm{CI}$ in zenith view. Bottom: results of the detailed classification scheme according to Fig. 14. (cloud holes (Z): clouds before or after the selected elevation sequence in zenith direction; cloud holes (LE): clouds before or after the selected elevation sequence at low elevation angles). Note that between 11:00 and 12:00 some data is missing due to instrumental problems. (Time is given as UTC.)

- Clear and cloudy periods as well as broken clouds are correctly identified.

- Thick clouds are identified for periods when dark clouds appear in the sky images.

- For clear days with low AOD (Fig. 17a) the blue sky is darker than for clear days with high AOD (Fig. 17c).

The results of the cloud classification scheme for all days are presented in Fig. 18 together with the diurnal variation of the lidar backscatter profiles (see Sect. 2.5). In general very good qualitative agreement is found. In some cases, slight differences are also found which might be attributed to different reasons like, e.g., the different locations, viewing directions and duty cycles of both instruments (see Sects. 2.1 and 2.5). Additional possible reasons for deviations are non-optimum choices of the selected thresholds or possible shortcomings in the interpretation of the lidar data for altitudes $<150 \mathrm{~m}$ (see Sect. 2.5).

In Table 3 an overview of the occurrences of the different cases for the complete measurement time series (12 June to 15 July 2009) is presented. Cloudy sky (continuous and broken clouds) was present during the majority of measurements $(58 \%)$. Most of the cloudy cases $(86 \%)$ were broken clouds; 
a) 24 June 2009

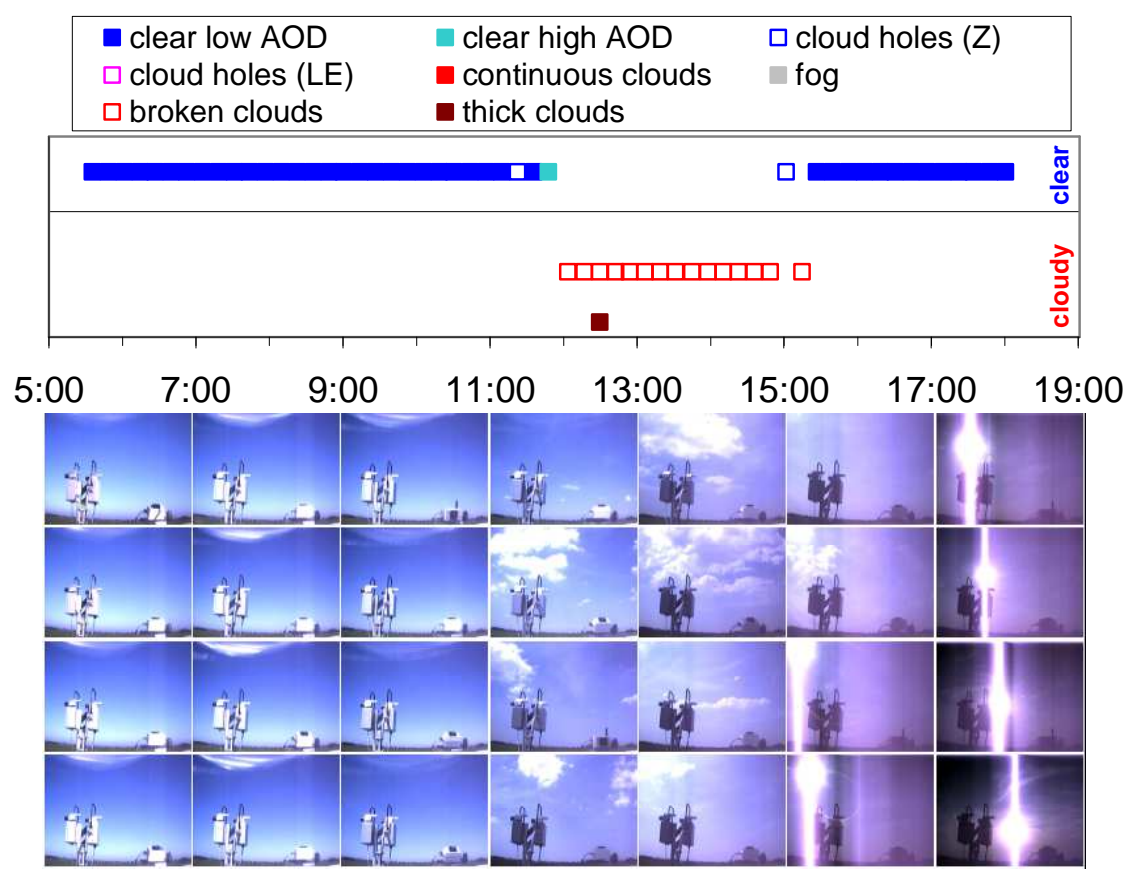

b) 15 June 2009

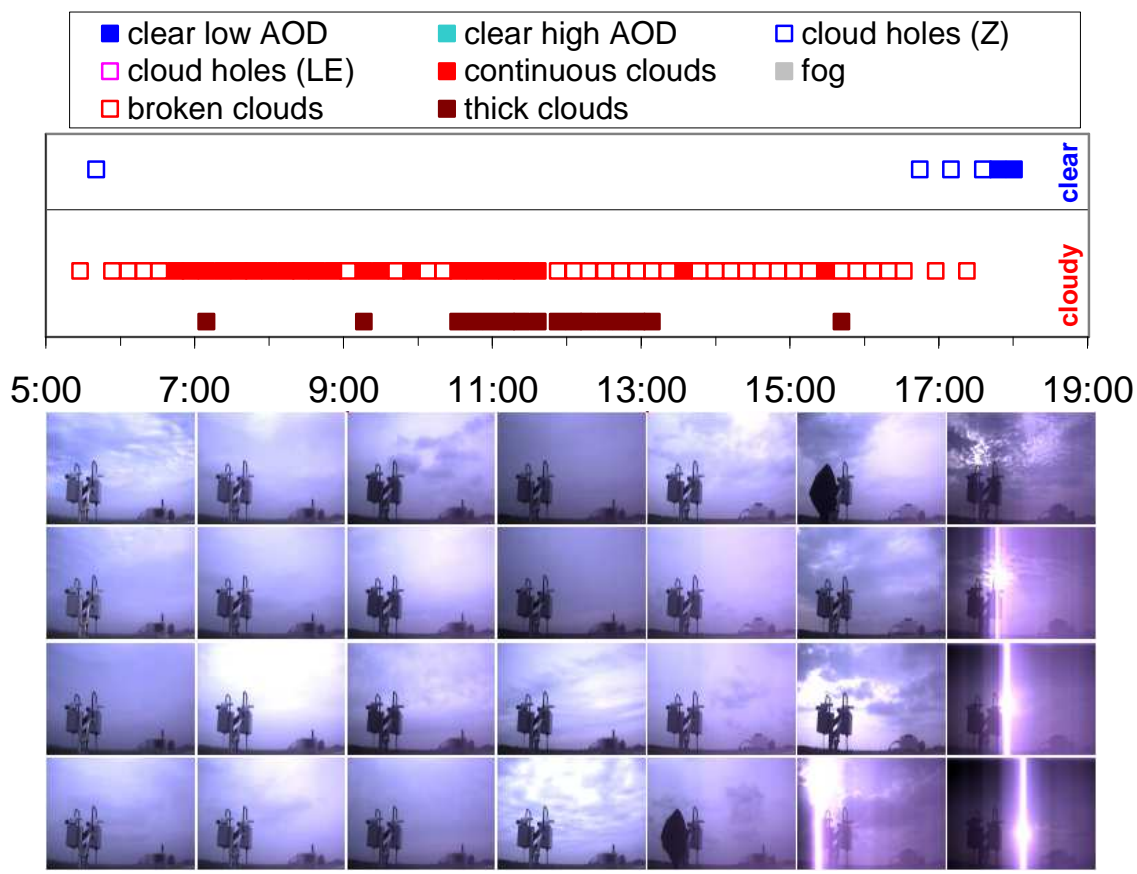

Fig. 17. Results of the cloud classification scheme for selected days (see Table 1). The sky images shown below are taken at intervals of $30 \mathrm{~min}$; each column of images belongs to the $2 \mathrm{~h}$ period of the time series of the cloud classification scheme (time is given as UTC). 
c) 02 July 2009

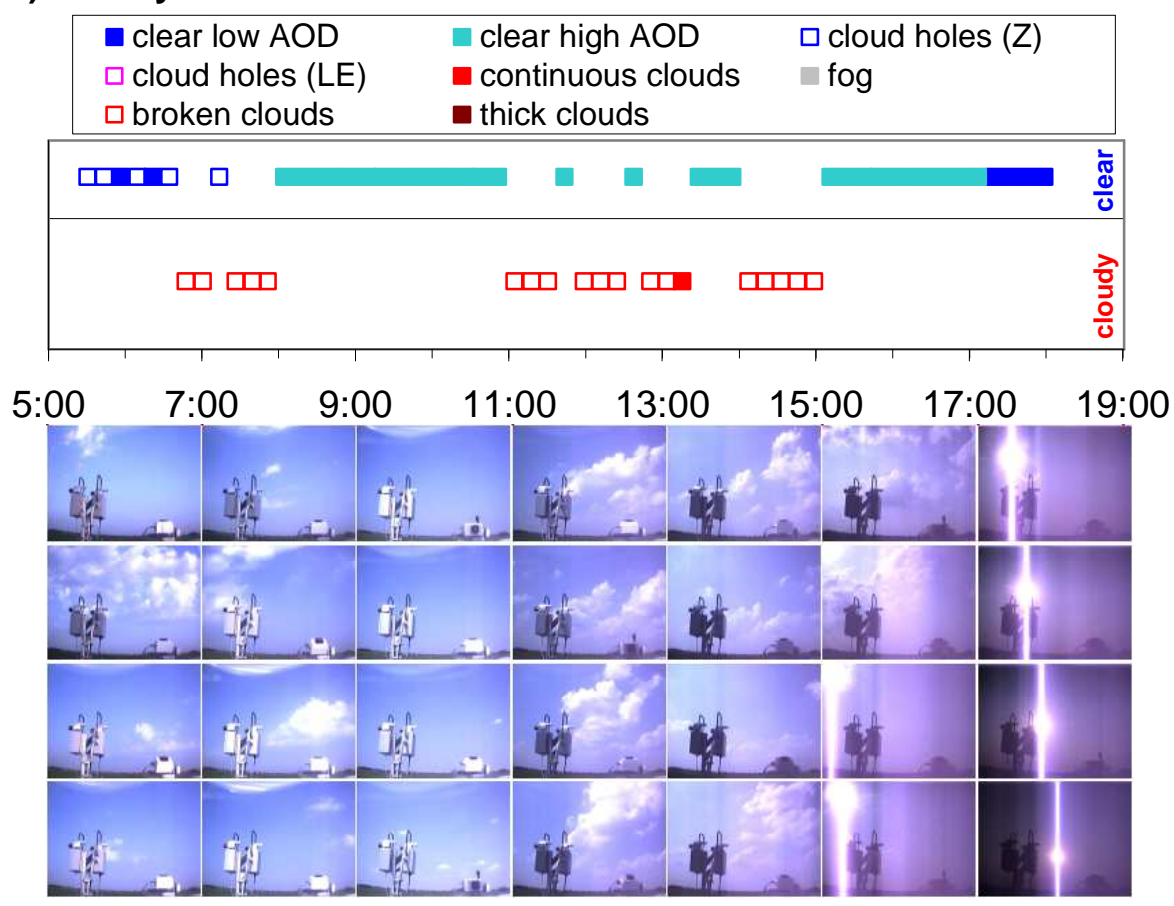

d) 28 June 2009

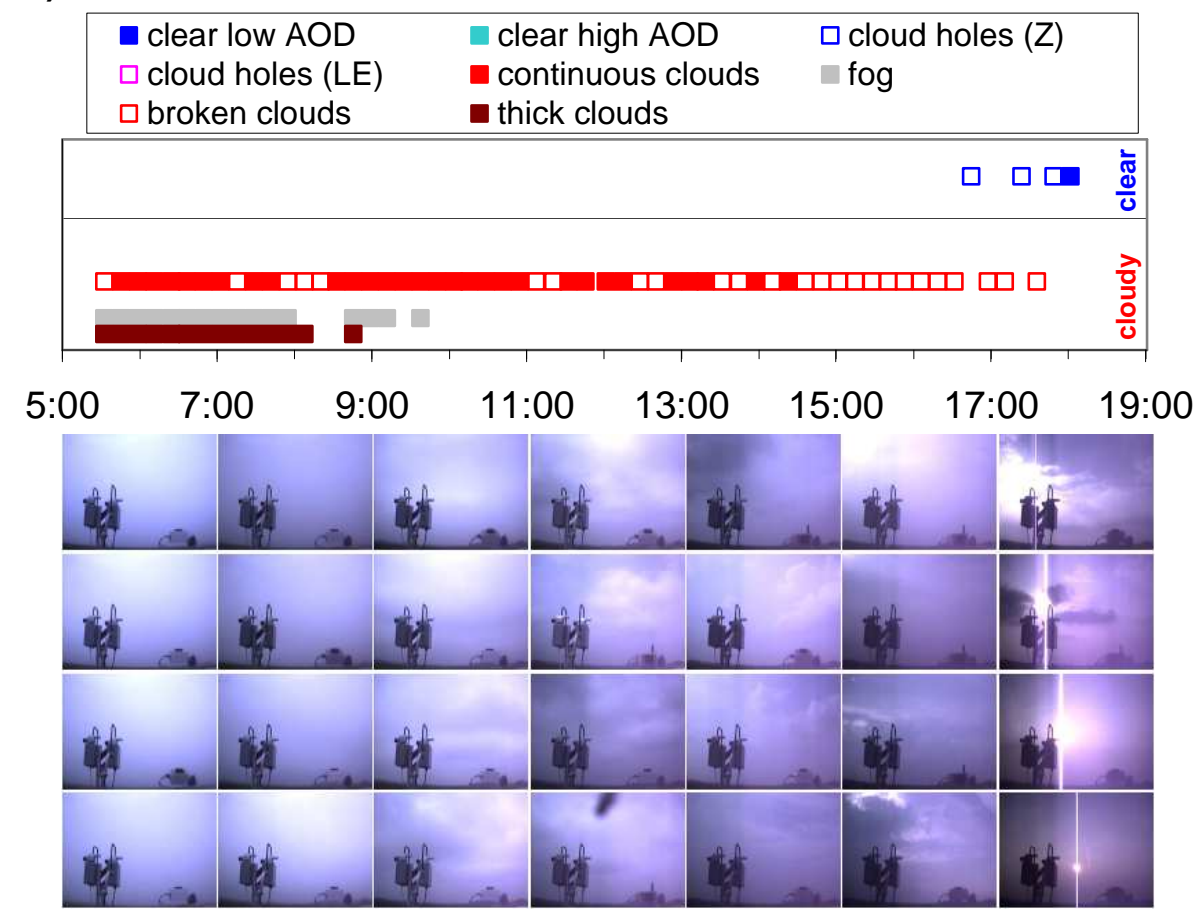

Fig. 17. Continued. Note that some data is missing on 18 June between 11:00 and 12:00 due to instrumental problems. 
Table 2. Suggested threshold values for the cloud classification scheme proposed in Fig. 14. (for the definition of the normalised CI, normalised radiance and normalised $\mathrm{O}_{4}$ DAMF, see Sects. 4.1 and 4.3.2).

\begin{tabular}{|c|c|c|}
\hline Quantity & Threshold & Remarks \\
\hline $\begin{array}{l}\text { Normalised colour index }(\mathrm{CI}) \text { in zenith direc- } \\
\text { tion }\end{array}$ & 0.65 & $\begin{array}{l}\text { - Values above threshold indicate a clear sky } \\
\text { - Threshold is valid for SZA } \leq 75^{\circ} \text { (measurements between } \\
\text { about 05:40 and 19:00) }\end{array}$ \\
\hline $\begin{array}{l}\text { Absolute value of the temporal smoothness in- } \\
\text { dicator (TSI) for CI for zenith view }\end{array}$ & $1.2 \times 10^{-7} \mathrm{~s}^{-2}$ & $\begin{array}{l}\text { - Values above threshold indicate rapidly changing cloud cover } \\
\text { (broken clouds or cloud holes) }\end{array}$ \\
\hline $\begin{array}{l}\text { Sum of the absolute values of the TSI for CI for } \\
\text { all non-zenith viewing directions }\end{array}$ & $3.3 \times 10^{-7}$ & $\begin{array}{l}\text { - Values above threshold indicate rapidly changing cloud cover } \\
\text { (broken clouds or cloud holes) }\end{array}$ \\
\hline Difference between maximum and minimum CI & 0.14 & - Values below threshold indicate continuous cloud cover \\
\hline $\begin{array}{l}\text { Difference between maximum and minimum } \\
\mathrm{O}_{4} \text { DAMF }\end{array}$ & 0.37 & - Values below threshold indicate fog \\
\hline Normalised radiance in zenith direction & 0.9 & $\begin{array}{l}\text { - Values below threshold indicate optically thick clouds } \\
\text { - Probably significant SZA dependence }\end{array}$ \\
\hline Normalised $\mathrm{O}_{4}$ DAMF in zenith direction & 0.74 & - Values above threshold indicate optically thick clouds \\
\hline
\end{tabular}

e) 18 June 2009

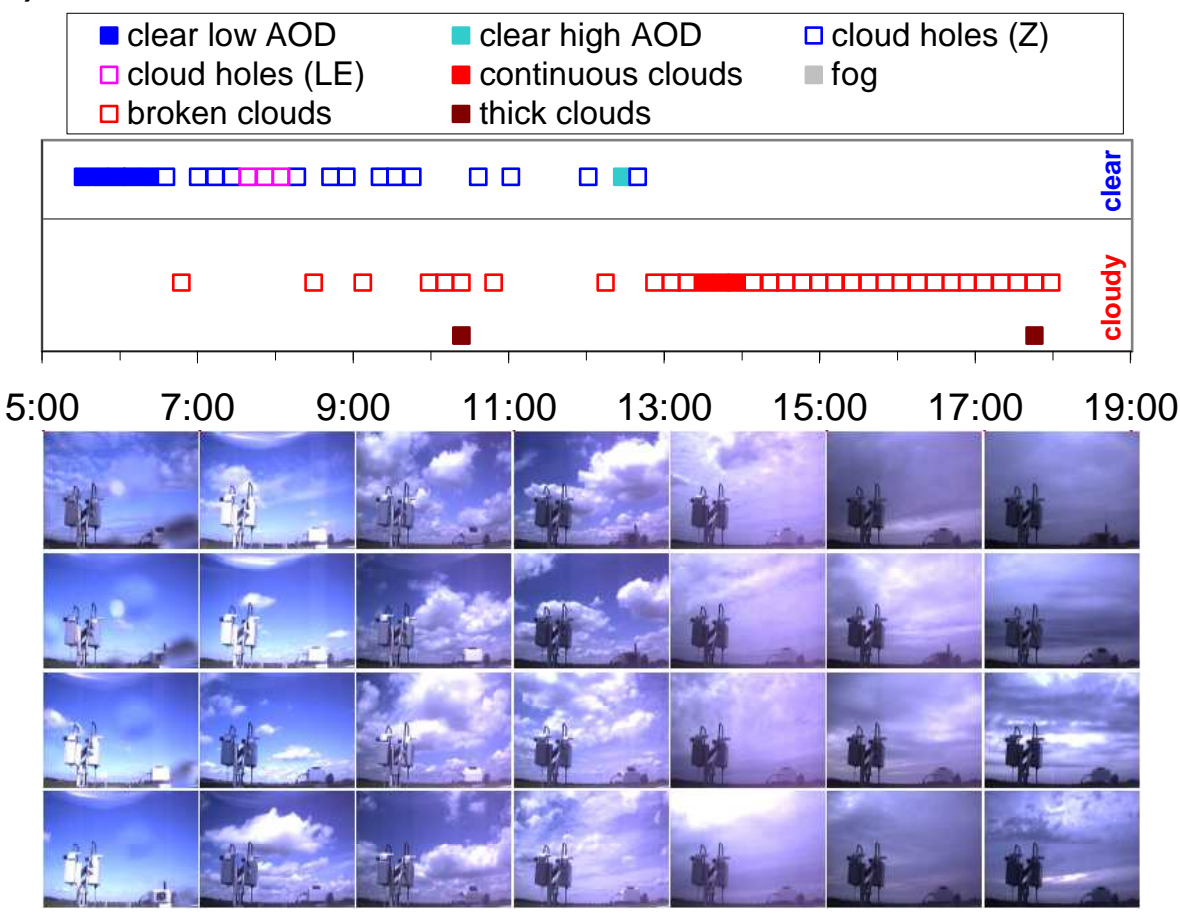

Fig. 17. Continued.

continuous cloud cover was found for $14 \%$ of all cloudy cases. Thick clouds were identified for $23 \%$ of all cloudy cases. Completely clear sky (with either low or high AOD) was found for about $20 \%$ of all measurements. Interestingly, the fraction of completely clear-sky observations derived from visual inspection of the web camera images was much smaller (only $7 \%$ ). The difference can be explained by the fact that thin clouds far away from the measurement location 


\begin{tabular}{|c|c|c|}
\hline - clear low AOD & clear high AOD & $\square$ cloud holes (Z) \\
\hline $\begin{array}{l}\square \text { cloud holes (LE) } \\
\square \text { broken clouds }\end{array}$ & $\begin{array}{l}\text { continuous clouds } \\
\text { thick clouds }\end{array}$ & fog \\
\hline
\end{tabular}

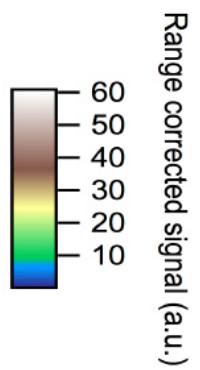

12 June 2009
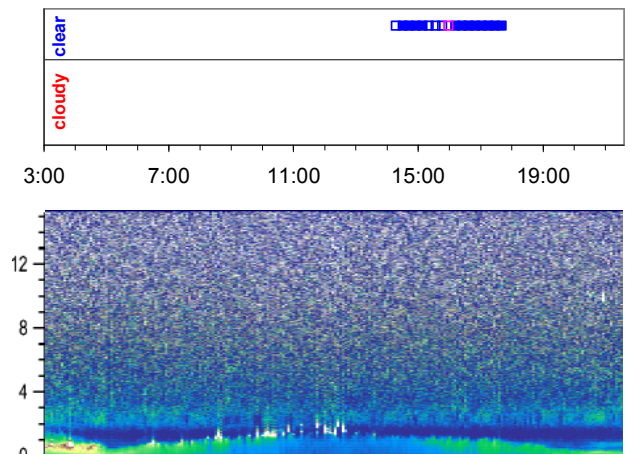

14 June 2009
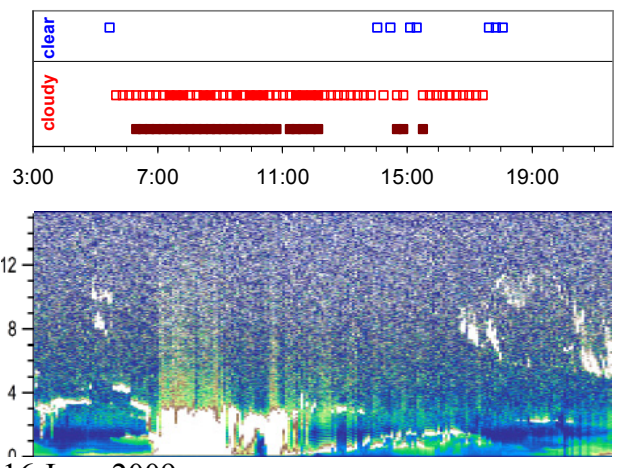

16 June 2009
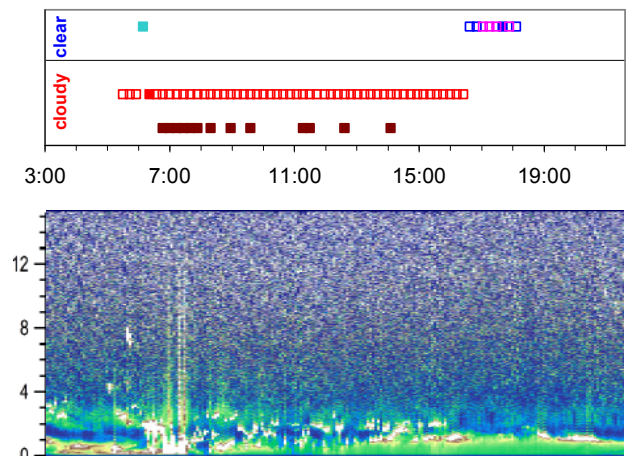

13 June 2009
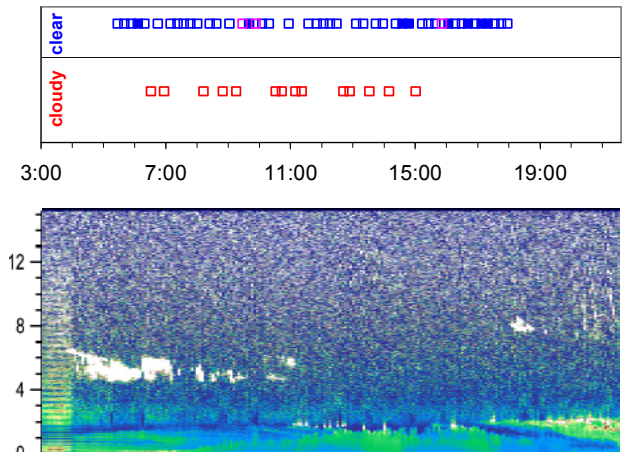

15 June 2009
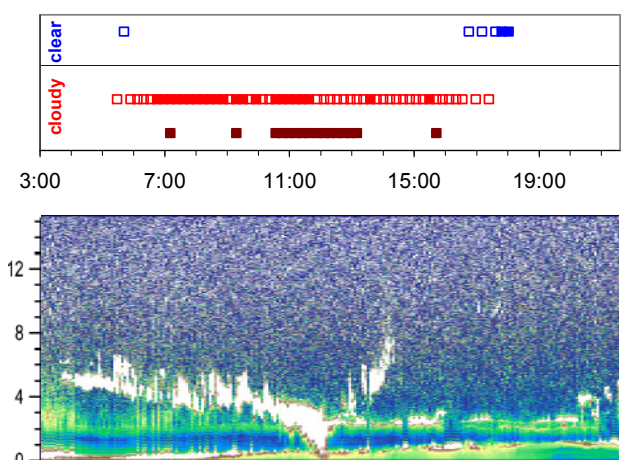

17 June 2009
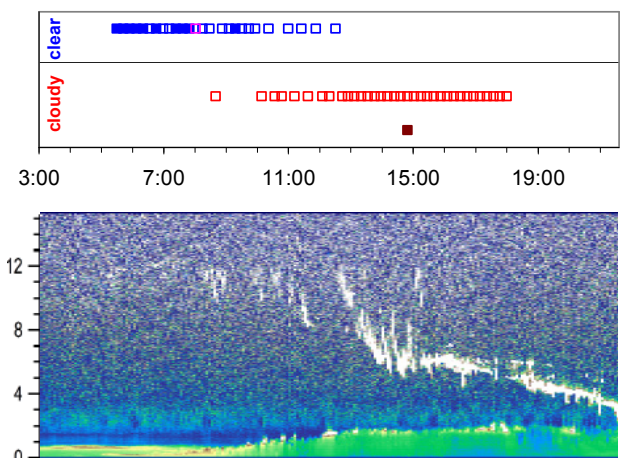

Fig. 18. Results of the cloud classification for all days of the campaign (time is given as UTC) together with the backscatter signal measured by the backscatter lidar between 0 and $15 \mathrm{~km}$. Note that on some days (10 June, 18 June, 21 June, 10 July) some data is missing due to instrumental problems. 


$\begin{array}{lll}\square \text { clear low AOD } & \text { clear high AOD } & \square \text { cloud holes }(\mathrm{Z}) \\ \square \text { cloud holes (LE) } & \text { continuous clouds } & \text { fog } \\ \square \text { broken clouds } & \text { thick clouds } & \end{array}$

18 June 2009
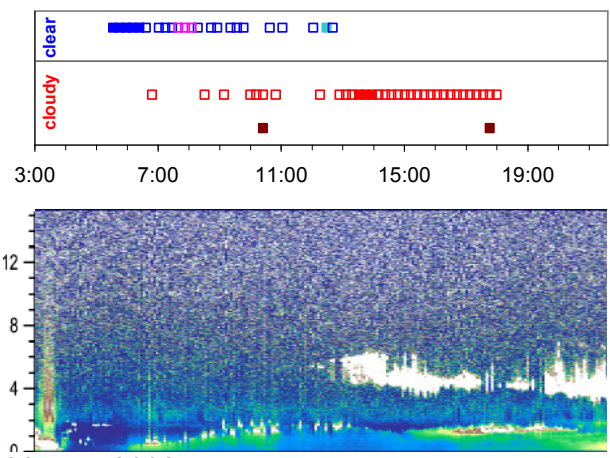

20 June 2009
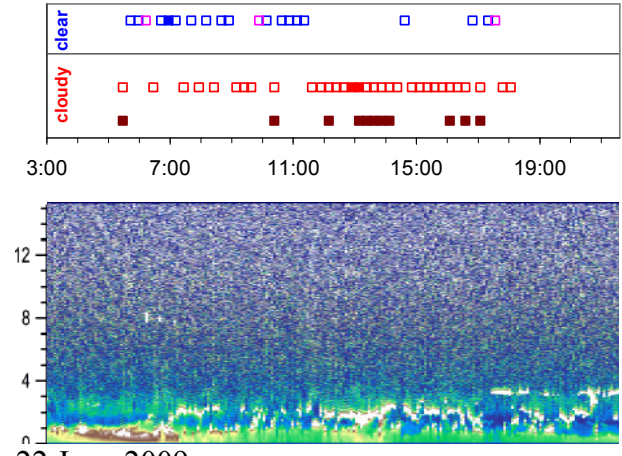

22 June 2009
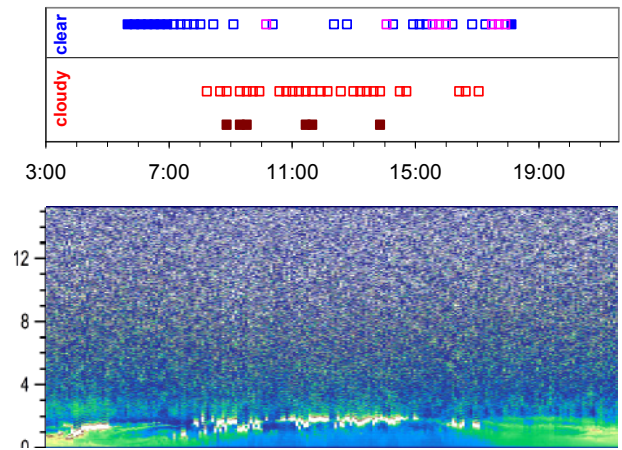

19 June 2009
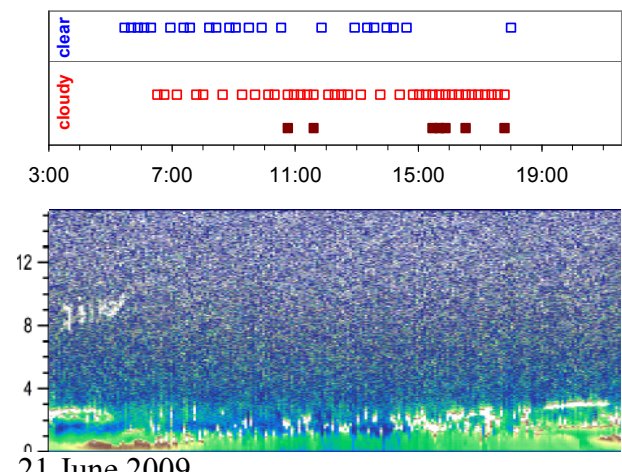

21 June 2009
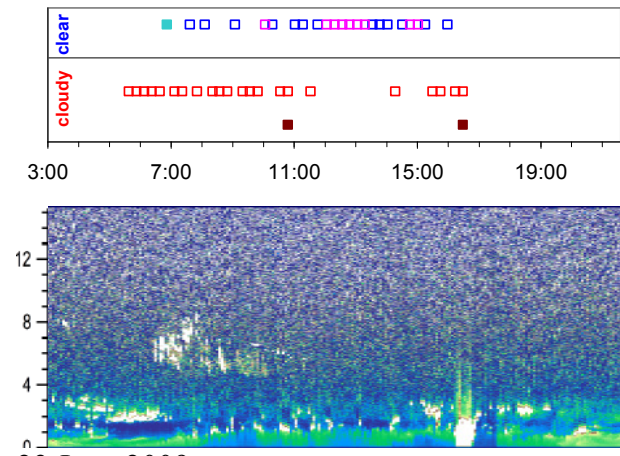

23 June 2009
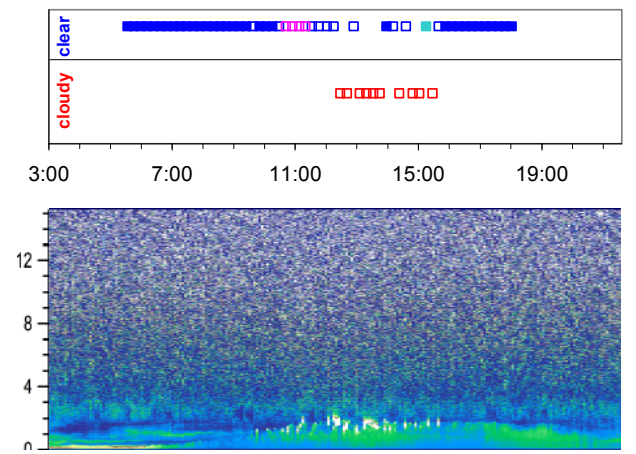

Fig. 18. Continued. 
- clear low AOD

$\square$ cloud holes (LE)

$\square$ broken clouds clear high AOD $\square$ cloud holes $(Z)$

- continuous clouds fog

thick clouds
24 June 2009
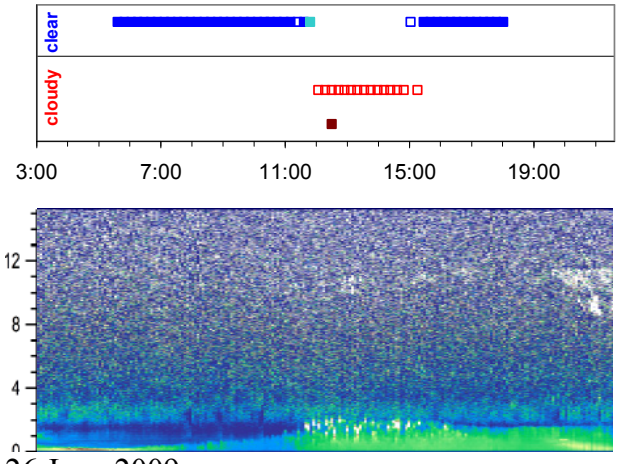

26 June 2009
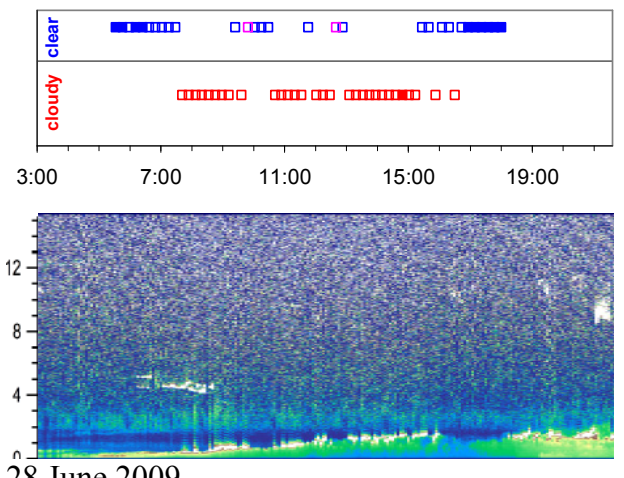

28 June 2009
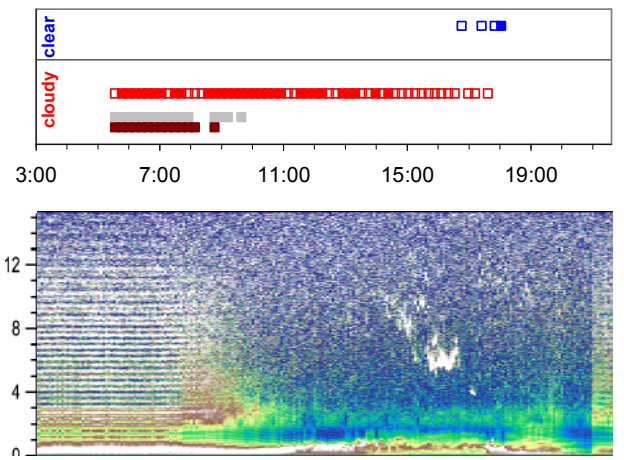

25 June 2009
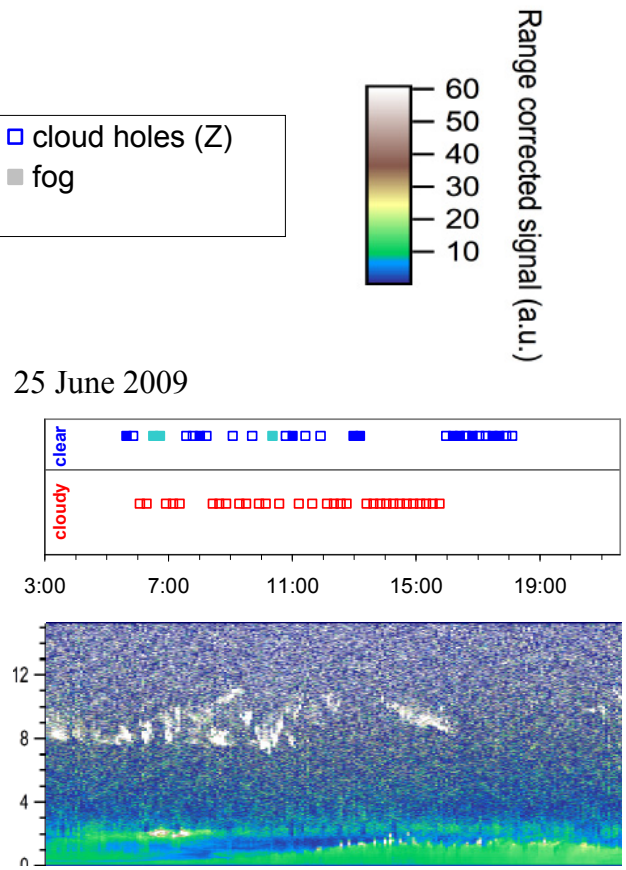

27 June 2009
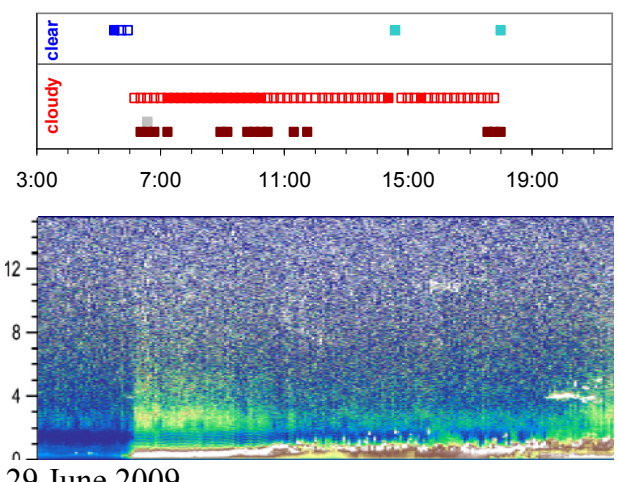

29 June 2009
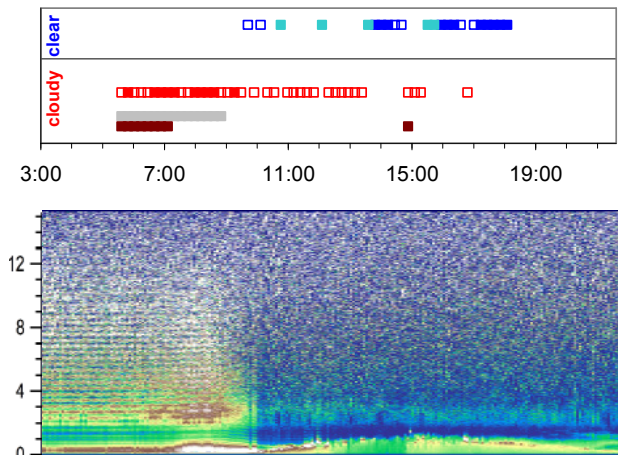

Fig. 18. Continued. 


\begin{tabular}{|c|c|c|}
\hline clear low AOD & clear high AOD & $\square$ cloud holes $(Z)$ \\
\hline$n$ cloud & thick clouds & \\
\hline
\end{tabular}

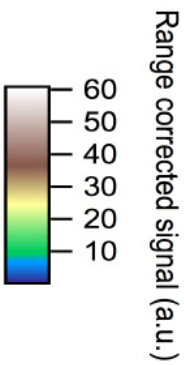

30 June 2009
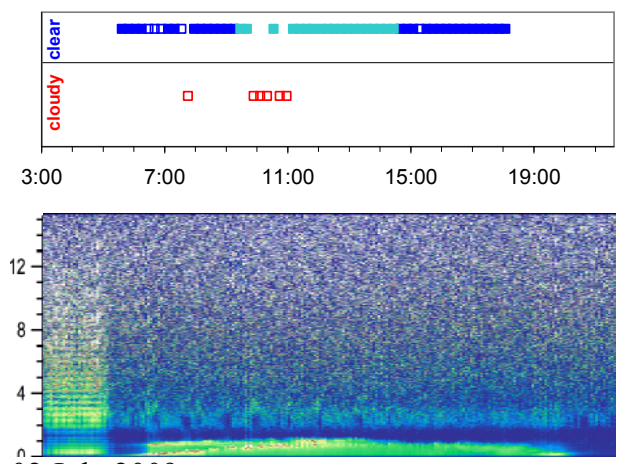

02 July 2009
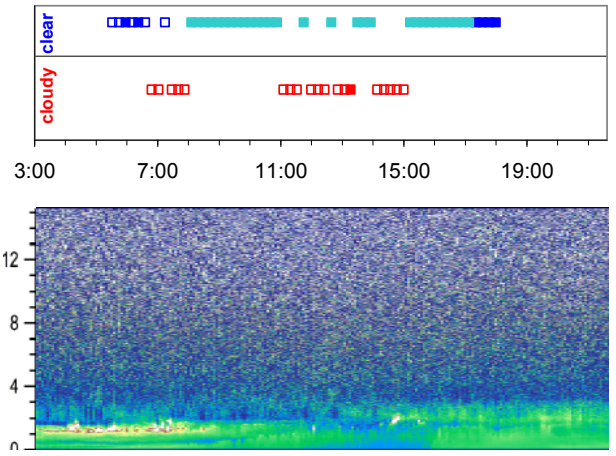

04 July 2009
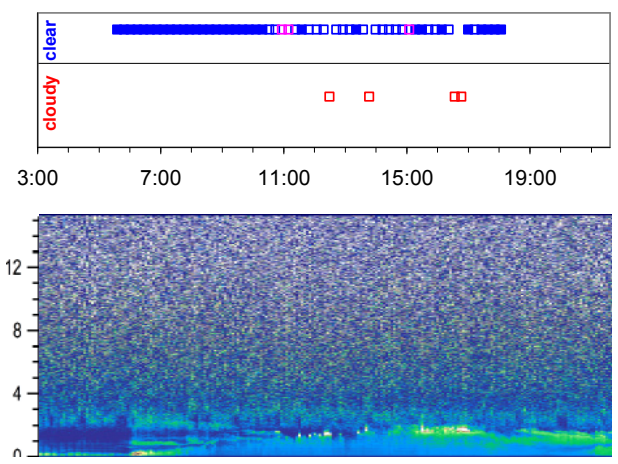

01 July 2009
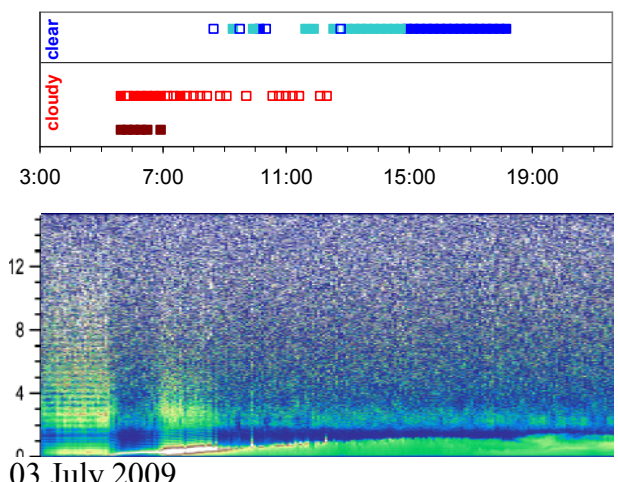

03 July 2009
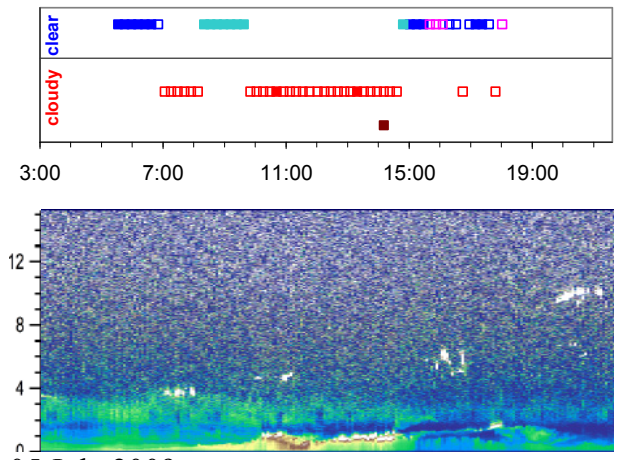

05 July 2009
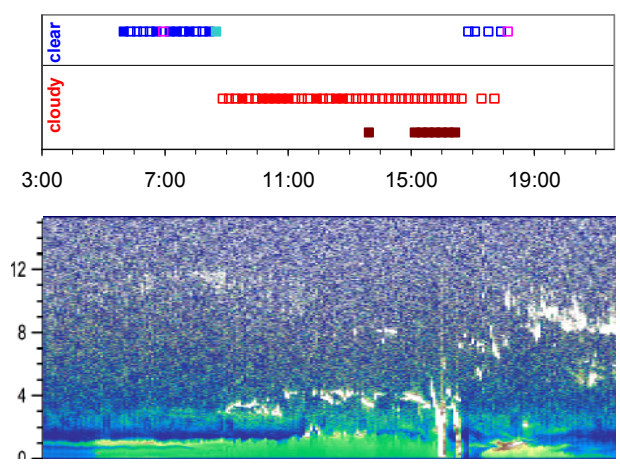

Fig. 18. Continued. 


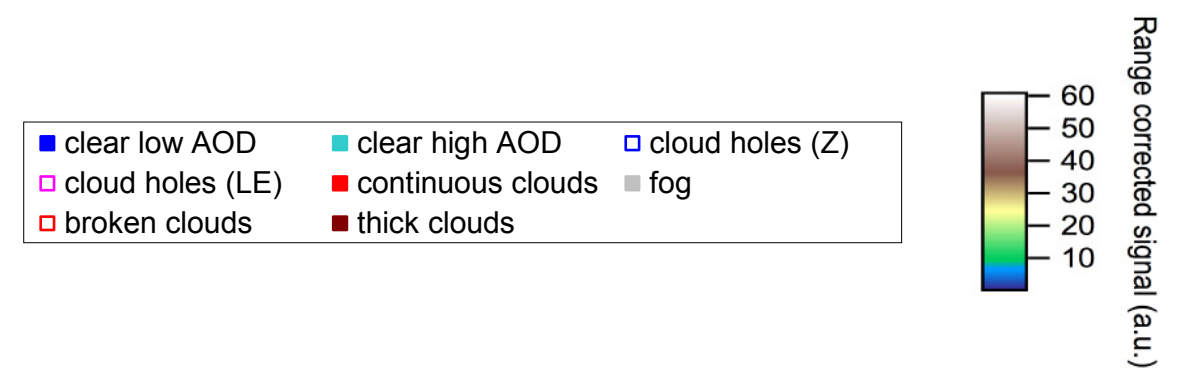

06 July 2009
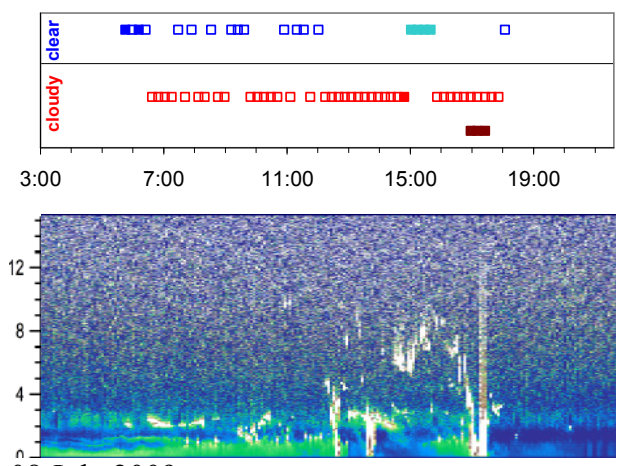

08 July 2009
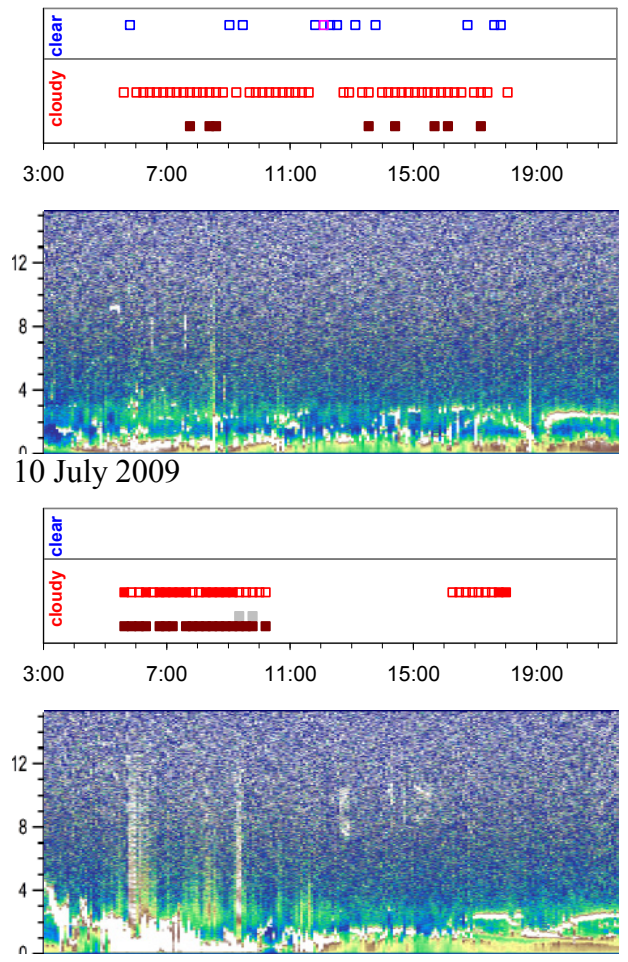

07 July 2009
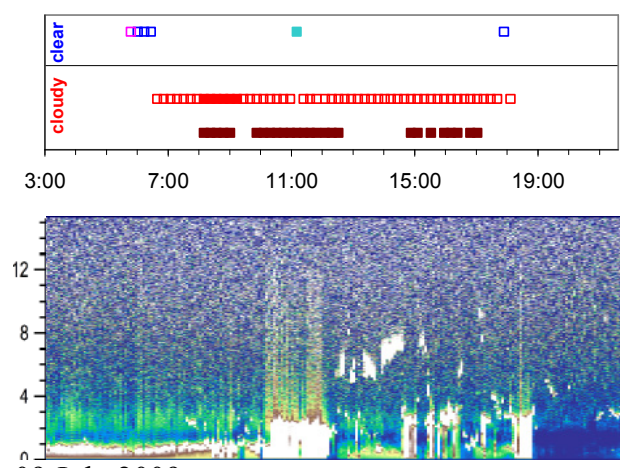

09 July 2009
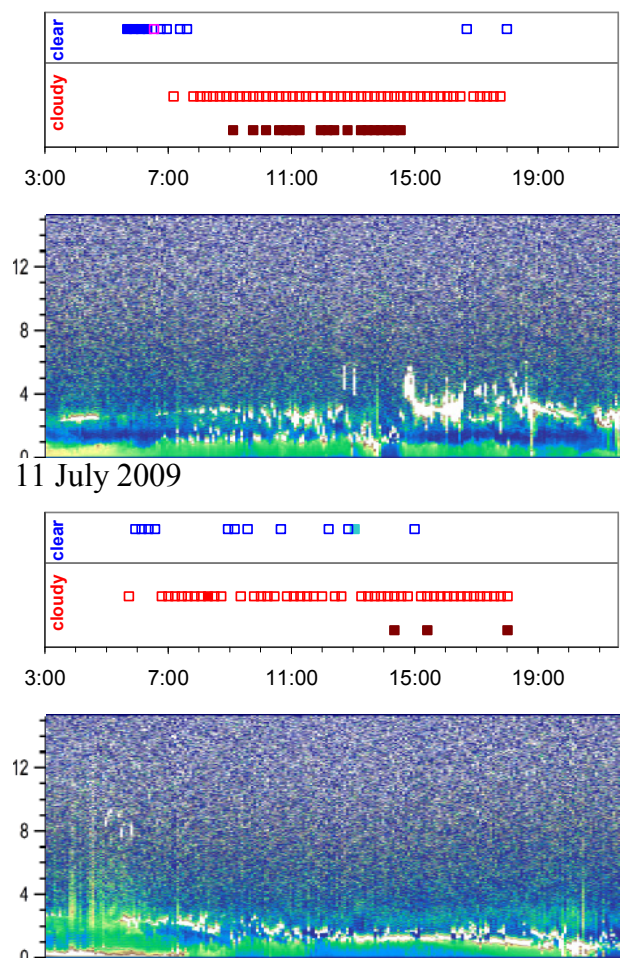

Fig. 18. Continued. 

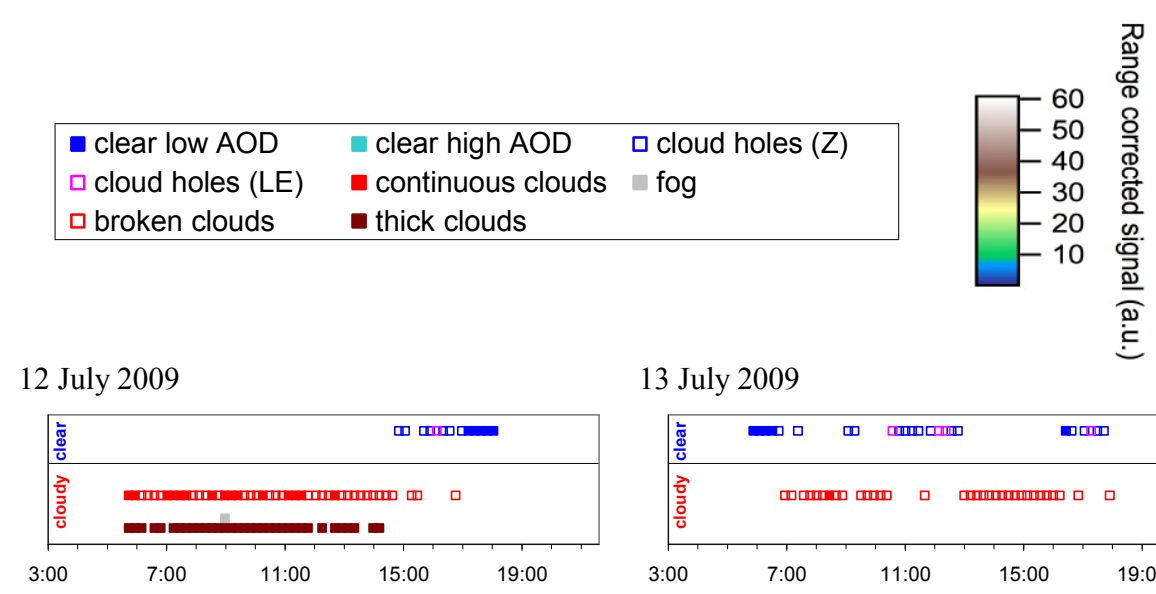

13 July 2009

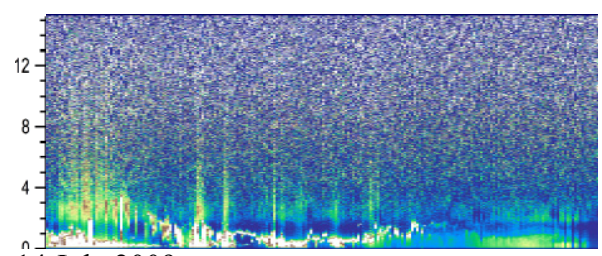

14 July 2009
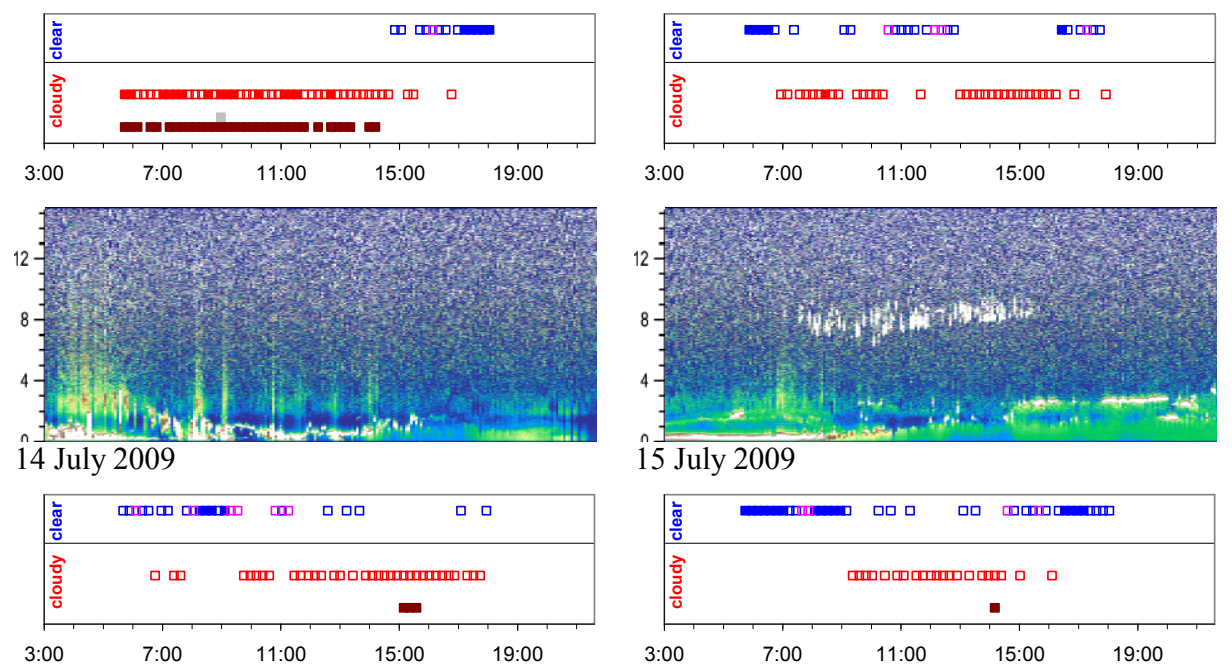

15 July 2009
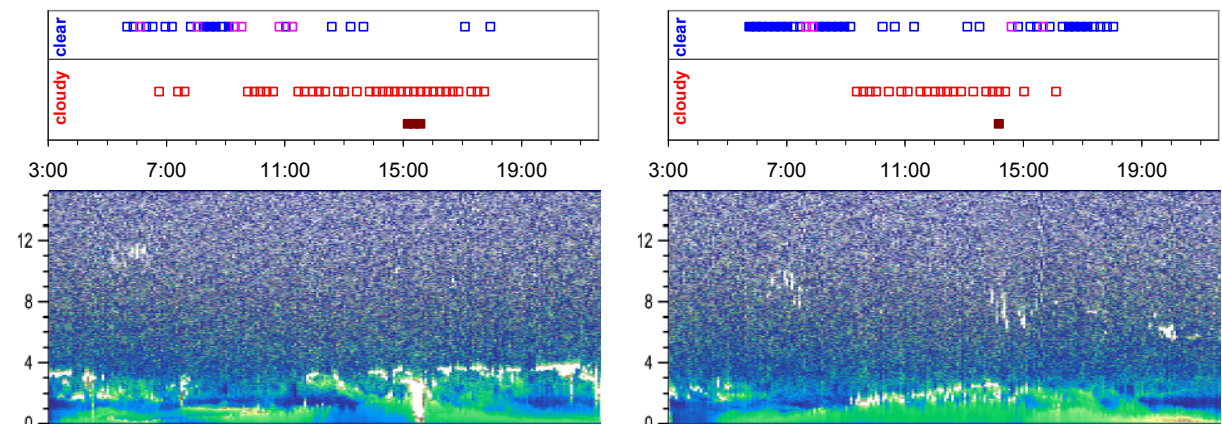

Fig. 18. Continued.

(or small cloud patches outside the field of view of the instrument) are not detected by our classification scheme, but can be clearly seen in the web camera images (e.g. on the morning of 18 June 2009; see Fig. 17e). Fortunately, such clouds obviously have a negligible influence on the MAXDOAS measurements. The remaining $22 \%$ of all measurements were cases with a clear sky in zenith direction but clouds present directly before or after the selected measurement (cloud holes).

\section{Conclusions}

We developed a classification scheme for clouds using MAXDOAS measurements. It is based on the measured radiance, colour index $(\mathrm{CI})$ and the retrieved $\mathrm{O}_{4}$ absorption. In principle measurements of the Ring effect could also be considered, but such observations do not add much additional information.
The presence of clouds can be identified by comparing the measured quantities to their respective clear-sky reference values. Here, zenith observations of the $\mathrm{CI}$ are especially useful, because the $\mathrm{CI}$ is affected by clouds in an unambiguous way, while the other quantities can be both enhanced or decreased in the presence of clouds (depending on the cloud properties). Thus, cloud discrimination schemes should be primarily based on zenith observations of the CI (see also Gielen et al., 2013).

Another way to identify clouds is to investigate the temporal variation of the measured quantities. Usually cloud properties (e.g. OD or altitude) change rapidly with time. Thus, in the presence of clouds the observed quantities usually show much larger variations than under a clear sky. In the presence of broken clouds these variations are especially strong.

A third possibility for the identification of clouds is to investigate the smoothness of the elevation dependence of individual elevation sequences. This method also investigates the inhomogeneity of cloud properties. However, since it does 
Table 3. Occurrences and relative fractions of the different cases retrieved by our cloud classification scheme during the whole period of measurements (12 June-15 July 2009). (Note that the classifications "thick clouds" and "fog" can appear for both continuous and broken clouds.)

\begin{tabular}{|c|c|c|c|c|}
\hline \multirow[b]{2}{*}{ Case } & \multicolumn{2}{|c|}{ Sophisticated scheme } & \multicolumn{2}{|c|}{ Simple scheme } \\
\hline & $\begin{array}{l}\text { Number of } \\
\text { elevation } \\
\text { sequences }\end{array}$ & Relative fraction & $\begin{array}{l}\text { Number of } \\
\text { elevation } \\
\text { sequences }\end{array}$ & Relative fraction \\
\hline Total & 1909 & $100 \%$ & 1909 & $100 \%$ \\
\hline Clear & 804 & $42.1 \%$ & 712 & $37.3 \%$ \\
\hline Clear low AOD & 293 & $15.3 \%$ & 358 & $18.7 \%$ \\
\hline Clear high AOD & 92 & $4.8 \%$ & & \\
\hline Cloud holes (high elevation) & 354 & $18.5 \%$ & 354 & $18.5 \%$ \\
\hline Cloud holes (low elevation) & 65 & $3.4 \%$ & & \\
\hline Cloudy & 1105 & $57.9 \%$ & 1197 & $62.7 \%$ \\
\hline Continuous clouds & 156 & $8.2 \%$ & 248 & $13.0 \%$ \\
\hline Broken clouds & 949 & $49.7 \%$ & 949 & $49.7 \%$ \\
\hline Fog & 36 & $1.9 \%$ & & \\
\hline Thick clouds & 257 & $13.5 \%$ & & \\
\hline
\end{tabular}

not add much additional information compared to the investigation of the temporal variability, it is not used in our cloud classification scheme.

The first step of our classification scheme is based on zenith observations. Zenith observations are well suited because their interpretation does not depend on the relative azimuth angle. In addition, broken clouds can be detected with the highest sensitivity from zenith observations. From zenith observations of the CI, clear and cloudy situations can be distinguished well (with the exception of situations with high aerosol load).

For the identification of more specific cases (e.g. the detection of fog or the discrimination of high AOD from clouds), measurements at low elevation angles are also used. If the temporal variation is also investigated for non-zenith viewing directions, the identification of clouds becomes possible even for individual observations.

One important aspect of our cloud classification scheme (and probably of cloud classification schemes in general) is the determination of suitable clear-sky reference values and threshold values for the temporal variability. In this study, we use results of radiative transfer simulations for the clearsky reference values. The selection of the various thresholds (see Table 2) depends on the "intuition" of the programmer, the available independent cloud information and the meteorological conditions of the measurement location. In the future, cloud classification schemes should be standardised (e.g. with respect to the choice of clear-sky reference values and the wavelengths used for radiance and CI) to allow a direct comparison of the cloud classification results.

We applied our cloud classification scheme to 34 days of MAX-DOAS measurements during CINDI in Cabauw in summer 2009. Very good agreement between the results of our algorithm and sky images from a web camera was found.
Good qualitative agreement is also found with profiles of a backscatter lidar. Most of the measurements (58\%) were affected by clouds; $20 \%$ were made in clear-sky conditions. For $22 \%$ of all measurements the MAX-DOAS telescopes observed a clear sky, but the proceeding and following measurements were affected by clouds (cloud holes). The high fraction of measurements under broken clouds $(50 \%)$ indicates an important problem of MAX-DOAS measurements: for such measurements the influence of clouds on the profile inversion of aerosols and trace gases is especially large. Consequently, the accuracy of the retrieved profiles is reduced, or even no meaningful profile inversion might be possible at all.

It should also be noted that for MAX-DOAS observations over snow- and ice-covered surfaces, the effects of clouds might be completely different from the effects described in this study. Future studies should also investigate cloud effects in such conditions.

Acknowledgements. We want to thank the organisers of the Cabauw Intercomparison campaign of Nitrogen Dioxide measuring Instruments (CINDI) in summer 2009 (http://www.knmi.nl/samenw/cindi/), especially Ankie Piters and Marc Kroon. Selami Yilmaz from IUP Heidelberg made the web camera images, which were of great importance for this study. We want to thank our colleagues Clio Gielen, Michel van Roozendael from BIRA, Brussels, and Andreas Richter and Folkard Wittrock from IUP Bremen for stimulating discussions. This study was carried out in the framework and with the support of the European project NORS (http://nors.aeronomie.be/index.php/project) within the European Community's Seventh Framework Programme under grant agreement no 284421. We thank Manuel Kopp for his valuable input on the TSI. We thank J. S. (Bas) Henzing and his staff for his effort in establishing and maintaining the Cabauw AERONET site used in this investigation. 
The service charges for this open access publication

have been covered by the Max Planck Society.

Edited by: P. Stammes

\section{References}

Apituley, A., van Lammeren, A., and Russchenberg, H.: High time resolution cloud measure- ments with lidar during CLARA, Phys. Chem. Ear., 25, 107-113, 2000.

Apituley, A., Wilson, K. M., Potma, C., Volten, H., and de Graaf, M.: Performance assessment and application of Caeli - a highperformance Raman lidar for diurnal profiling of water vapour, aerosols and clouds, in: Proceedings of the 8th ISTP, edited by: Apituley, A., Russchenberg, H. W. J., and Monna, W. A. A., S06O10, 2009.

Bogumil, K., Orphal, J., Homann, T., Voigt, S., Spietz, P., Fleischmann, O. C., Vogel, A., Hartmann, M., Bovensmann, H., Frerik, J., and Burrows, J. P.: "Measurements of molecular absorption spectra with the SCIAMACHY Pre-Flight Model: Instrument characterization and reference spectra for atmospheric remote sensing in the $230-2380 \mathrm{~nm}$ region", J. Photochem. Photobiol. A, 157, 167-184, 2003.

Clémer, K., Van Roozendael, M., Fayt, C., Hendrick, F., Hermans, C., Pinardi, G., Spurr, R., Wang, P., and De Mazière, M.: Multiple wavelength retrieval of tropospheric aerosol optical properties from MAXDOAS measurements in Beijing, Atmos. Meas. Tech., 3, 863-878, doi:10.5194/amt-3-863-2010, 2010.

Deutschmann, T., Beirle, S., Frieß, U., Grzegorski, M., Kern, C., Kritten, L., Platt, U., Pukite, J., Wagner, T., Werner, B., and Pfeilsticker, K.: The Monte Carlo Atmospheric Radiative Transfer Model McArtim: Introduction and Validation of Jacobians and 3D Features, J. Quant. Spectr. Rad. Transf., 112, 1119-1137, doi:10.1016/j.jqsrt.2010.12.009, 2011.

Dubovik, O., Holben, B. N., Eck, T. F., Smirnov, A., Kaufman, Y. J., King, M. D., Tanré, D., and Slutsker, I.: Variability of absorption and optical properties of key aerosol types observed in worldwide locations, J. Atmos. Sci., 59, 590-608, 2002.

Enell, C.-F., Steen, Å., Wagner, T., Frieß, U., Pfeilsticker, K., Platt, U., and Fricke, K.-H.: Occurrence of polar stratospheric clouds at Kiruna, Ann. Geophys., 17, 1457-1462, doi:10.1007/s00585999-1457-7, 1999.

Erle, F., Pfeilsticker, K., and Platt, U.: On the influence of tropospheric clouds on zenith scattered light measurements of stratospheric species, Geophys. Res. Lett., 22, 2725-2728, 1995.

Frieß, F., Monks, P. S., Remedios, J. J., Rozanov, A., Sinreich, R., Wagner, T., and Platt, U.: MAX-DOAS $\mathrm{O}_{4}$ measurements: A new technique to derive information on atmospheric aerosols, (II) Modelling studies, J. Geophys. Res., 111, D14203, doi:10.1029/2005JD006618, 2006.

Gielen, C., Van Roozendael, M., Hendrick, F., Fayt, C., Hermans, C., Pinardi, G., and Vlemmix, T.: Development of a cloud screening method for MAX-DOAS observations, presentation at the 6th international DOAS workshop, Boulder, 12-14 August 2013.

Grainger, J. F. and Ring, J.: Anomalous Fraunhofer line profiles, Nature, 193, p. 762, 1962.

Greenblatt, G. D., Orlando, J. J., Burkholder, J. B., and Ravishankara, A. R.: Absorption measurements of oxygen between 330 and 1140 nm, J. Geophys. Res., 95, 18577-18582, 1990.
Heckel, A., Richter, A., Tarsu, T., Wittrock, F., Hak, C., Pundt, I., Junkermann, W., and Burrows, J. P.: MAX-DOAS measurements of formaldehyde in the Po-Valley, Atmos. Chem. Phys., 5, 909918, doi:10.5194/acp-5-909-2005, 2005.

Holben, B. N., Tanre, D., Smirnov, A., Eck, T. F., Slutsker, I., Abuhassan, N., Newcomb, W. W., Schafer, J., Chatenet, B., Lavenue, F., Kaufman, Y. J., Vande, J., Castle, J., Setzer, A., Markham, B., Clark, D., Frouin, R., Halthore, R., Karnieli, A., O’Neill, N. T., Pietras, C., Pinker, R. T., Voss, K., and Zibordi, G.: An emerging ground-based aerosol climatology: Aerosol Optical Depth from AERONET, J. Geophys. Res., 106, 1206712097, 2001.

Hönninger, G., von Friedeburg, C., and Platt, U.: Multi axis differential optical absorption spectroscopy (MAX-DOAS), Atmos. Chem. Phys., 4, 231-254, doi:10.5194/acp-4-231-2004, 2004.

Irie, H., Kanaya, Y., Akimoto, H., Iwabuchi, H., Shimizu, A., and Aoki, K.: First retrieval of tropospheric aerosol profiles using MAX-DOAS and comparison with lidar and sky radiometer measurements, Atmos. Chem. Phys., 8, 341-350, doi:10.5194/acp-8341-2008, 2008.

Kattawar, G. W., Young, A. T., and Humphreys, T. J.: InelasticScattering in Planetary-Atmospheres. 1. The Ring Effect, without Aerosols, Astrophysical J., 243, 1049-1057, 1981.

Li, X., Brauers, T., Shao, M., Garland, R. M., Wagner, T., Deutschmann, T., and Wahner, A.: MAX-DOAS measurements in southern China: retrieval of aerosol extinctions and validation using ground-based in-situ data, Atmos. Chem. Phys., 10, 20792089, doi:10.5194/acp-10-2079-2010, 2010.

Nakajima, T. and King, M. D.: Determination of the OpticalThickness and Effective Particle Radius of Clouds from Reflected Solar-Radiation Measurements .1. Theory, J. Atmos. Sci., 47, 1878-1893, 1990.

Mishchenko, M. I., Lacis, A. A., and Travis, L. D.: Errors induced by the neglect of polarization in radiance calculations for Rayleigh-scattering atmospheres, J. Quant. Spectrosc. Ra., 51, 491-510, doi:10.1016/0022-4073(94)90149-X, 1994.

Platt, U. and Stutz, J., Differential Optical Absorption Spectroscopy, Principles and Applications, Springer, Berlin, 2008.

Piters, A. J. M., Boersma, K. F., Kroon, M., Hains, J. C., Van Roozendael, M., Wittrock, F., Abuhassan, N., Adams, C., Akrami, M., Allaart, M. A. F., Apituley, A., Beirle, S., Bergwerff, J. B., Berkhout, A. J. C., Brunner, D., Cede, A., Chong, J., Clémer, K., Fayt, C., Frieß, U., Gast, L. F. L., Gil-Ojeda, M., Goutail, F., Graves, R., Griesfeller, A., Großmann, K., Hemerijckx, G., Hendrick, F., Henzing, B., Herman, J., Hermans, C., Hoexum, M., van der Hoff, G. R., Irie, H., Johnston, P. V., Kanaya, Y., Kim, Y. J., Klein Baltink, H., Kreher, K., de Leeuw, G., Leigh, R., Merlaud, A., Moerman, M. M., Monks, P. S., Mount, G. H., Navarro-Comas, M., Oetjen, H., Pazmino, A., Perez-Camacho, M., Peters, E., du Piesanie, A., Pinardi, G., Puentedura, O., Richter, A., Roscoe, H. K., Schönhardt, A., Schwarzenbach, B., Shaiganfar, R., Sluis, W., Spinei, E., Stolk, A. P., Strong, K., Swart, D. P. J., Takashima, H., Vlemmix, T., Vrekoussis, M., Wagner, T., Whyte, C., Wilson, K. M., Yela, M., Yilmaz, S., Zieger, P., and Zhou, Y.: The Cabauw Intercomparison campaign for Nitrogen Dioxide measuring Instruments (CINDI): design, execution, and early results, Atmos. Meas. Tech., 5, 457-485, doi:10.5194/amt-5-457-2012, 2012. 
Roscoe, H. K., Van Roozendael, M., Fayt, C., du Piesanie, A., Abuhassan, N., Adams, C., Akrami, M., Cede, A., Chong, J., Clémer, K., Friess, U., Gil Ojeda, M., Goutail, F., Graves, R., Griesfeller, A., Grossmann, K., Hemerijckx, G., Hendrick, F., Herman, J., Hermans, C., Irie, H., Johnston, P. V., Kanaya, Y., Kreher, K., Leigh, R., Merlaud, A., Mount, G. H., Navarro, M., Oetjen, H., Pazmino, A., Perez-Camacho, M., Peters, E., Pinardi, G., Puentedura, O., Richter, A., Schönhardt, A., Shaiganfar, R., Spinei, E., Strong, K., Takashima, H., Vlemmix, T., Vrekoussis, M., Wagner, T., Wittrock, F., Yela, M., Yilmaz, S., Boersma, F., Hains, J., Kroon, M., Piters, A., and Kim, Y. J.: Intercomparison of slant column measurements of $\mathrm{NO}_{2}$ and $\mathrm{O}_{4}$ by MAX-DOAS and zenith-sky UV and visible spectrometers, Atmos. Meas. Tech., 3, 1629-1646, doi:10.5194/amt-3-1629-2010, 2010.

Sarkissian, A., Pommereau, J.-P., and Goutail, F.: Identification of polar stratospheric clouds from the ground by visible spectrometry, Geophys. Res. Lett., 18, 779-782, 1991.

Sarkissian, A., Pommereau, J., Goutail, F., and Kyrö, E.: PSC and volcanic aerosol observations during EASOE by UV-visible ground-based spectrometry, Geophys. Res. Lett., 21, 1319-1322, 1994.

Schaap, M., Apituley, A., Timmermans, R. M. A., Koelemeijer, R. B. A., and de Leeuw, G.: Exploring the relation between aerosol optical depth and $\mathrm{PM}_{2.5}$ at Cabauw, the Netherlands, Atmos. Chem. Phys., 9, 909-925, doi:10.5194/acp-9-909-2009, 2009.

Solomon, S., Schmeltekopf, A. L., and Sanders, R. W.: On the interpretation of zenith sky absorption measurements, J. Geophys. Res, 92, 8311-8319, 1987.

Vandaele, A. C., Hermans, C., Simon, P. C., Van Roozendael, M., Guilmot, J. M., Carleer, M., andColin, R.: Fourier transform measurement of $\mathrm{NO}_{2}$ absorption cross-section in the visible range at room temperature, J. Atmos. Chem. 25, 289-305, 1996.
Wagner, T., Erle, F., Marquard, L., Otten, C., Pfeilsticker, K., Senne, T., Stutz, J., and Platt, U.: Cloudy sky optical paths as derived from differential optical absorption spectroscopy observations, J. Geophys. Res., 103, 25307-25321, 1998.

Wagner, T., Dix, B., Friedeburg, C. V., Frieß, U., Sanghavi, S., Sinreich, R., and Platt, U.: MAX-DOAS $\mathrm{O}_{4}$ measurements - a new technique to derive information on atmospheric aerosols. (I) Principles and information content, J. Geophys. Res., 109, D22205, doi:10.1029/2004JD004904, 2004.

Wagner, T., Beirle, S., and Deutschmann, T.: Three-dimensional simulation of the Ring effect in observations of scattered sun light using Monte Carlo radiative transfer models, Atmos. Meas. Tech., 2, 113-124, doi:10.5194/amt-2-113-2009, 2009.

Wagner, T., Beirle, S., Brauers, T., Deutschmann, T., Frieß, U., Hak, C., Halla, J. D., Heue, K. P., Junkermann, W., Li, X., Platt, U., and Pundt-Gruber, I.: Inversion of tropospheric profiles of aerosol extinction and $\mathrm{HCHO}$ and $\mathrm{NO}_{2}$ mixing ratios from MAX-DOAS observations in Milano during the summer of 2003 and comparison with independent data sets, Atmos. Meas. Tech., 4, 2685-2715, doi:10.5194/amt-4-2685-2011, 2011.

Winterrath, T., Kurosu, T. P., Richter, A., and Burrows, J. P.: Enhanced $\mathrm{O}_{3}$ and $\mathrm{NO}_{2}$ in thunderstorm clouds: convection or production?, Geophys. Res. Lett., 26, 1291-1294, 1999.

Wittrock, F., Oetjen, H., Richter, A., Fietkau, S., Medeke, T., Rozanov, A., and Burrows, J. P.: MAX-DOAS measurements of atmospheric trace gases in Ny-Älesund - Radiative transfer studies and their application, Atmos. Chem. Phys., 4, 955-966, doi:10.5194/acp-4-955-2004, 2004. 